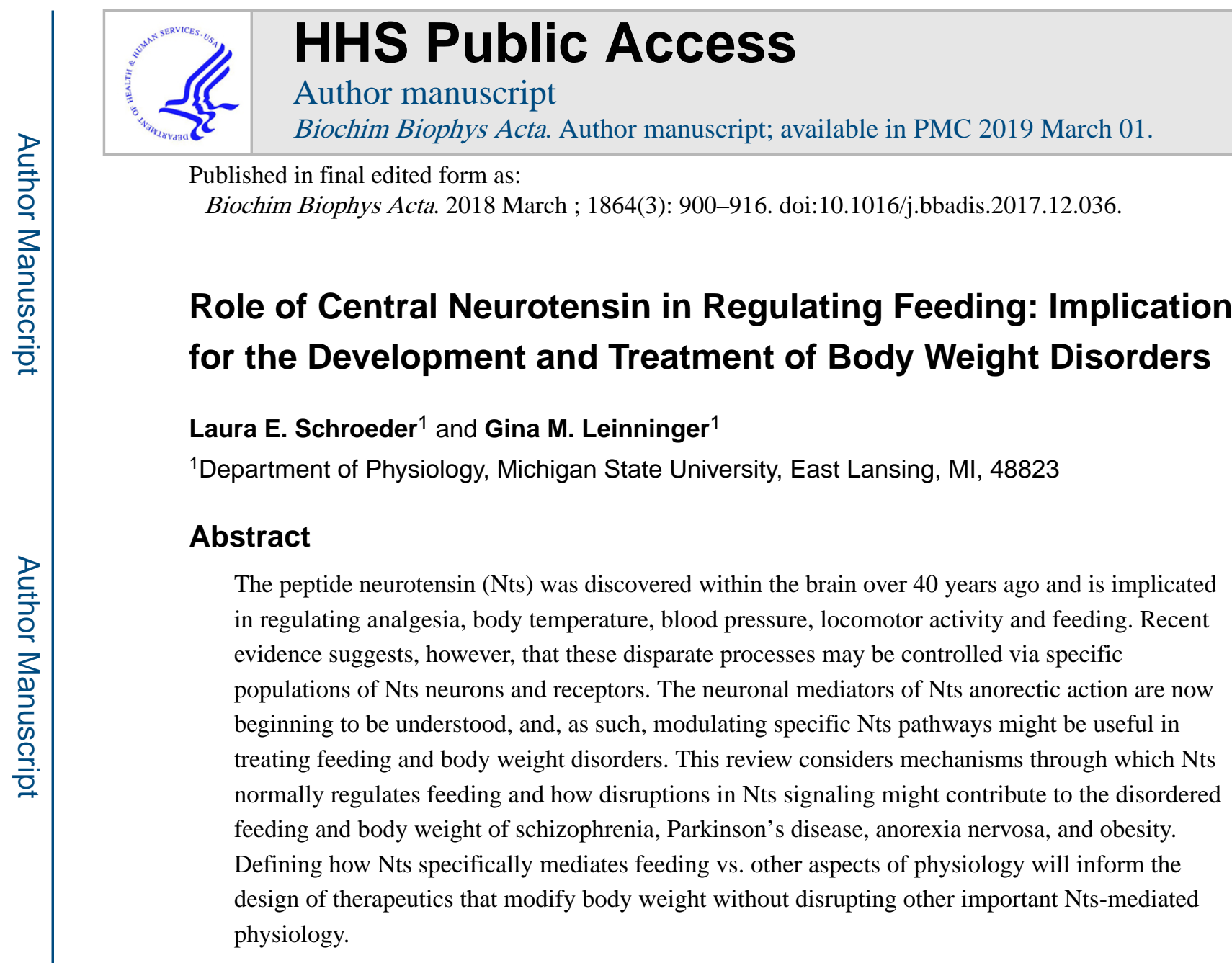

\title{
Keywords
}

Neurotensin receptor; dopamine; energy balance; obesity; anorexia

\section{Ingestive Behavior Impacts Health}

The physiological processes that sustain life constantly tap bodily energy reserves, which must be replaced via ingestion; hence, feeding is a compulsory behavior for survival. Decades of research have proven that the brain is the master-organizer of feeding behavior, vigilantly monitoring energy status and coordinating appropriate ingestive behavior. For example, fasting-induced hunger increases the motivation to find and ingest food, while stomach fullness or increased body fat cue the cessation of feeding. However, despite recognition that these processes take place, and the fact that eating and drinking are perhaps the most commonly performed behaviors in animals and humans, the precise mechanisms by which the brain orchestrates these processes remain incompletely understood.

Lead Contact and Correspondence: Gina M. Leinninger, PhD, Department of Physiology, Michigan State University, 567 Wilson Rd, BPS Bldg., Room 3183, East Lansing, MI 48824, Phone: 517-884-5123, Fax: 517-432-1967, leinning@msu.edu.

Publisher's Disclaimer: This is a PDF file of an unedited manuscript that has been accepted for publication. As a service to our customers we are providing this early version of the manuscript. The manuscript will undergo copyediting, typesetting, and review of the resulting proof before it is published in its final citable form. Please note that during the production process errors may be discovered which could affect the content, and all legal disclaimers that apply to the journal pertain. 
Defining the biology of ingestion is necessary not only to understand immediate survival but also to treat, and ultimately prevent, feeding dysregulation that endangers health and wellbeing. For example, intake of excess calories, along with insufficient physical activity and metabolic rate to consume them, results in increased adiposity. The rise in highly palatable, energy-dense foods, their ease of acquisition and the widespread increase in sedentary lifestyles have contributed to the worldwide rise in the overweight and obese [1]. Increased body weight, as assessed via body mass index, elevates risk of developing severe chronic conditions, including cardiovascular disease, type-2 diabetes, kidney disease, cancer and disability, and has been accountable for 4 million annual deaths [2]. Though lifestyle intervention is safe and somewhat effective in promoting weight loss, it is difficult to maintain and, as a result, has not been sufficient to counteract the overweight and obesity epidemic. Bariatric surgery is currently the most effective option to treat obesity; however, not all patients are able to undergo such procedures because of cost, complications, or restrictive guidelines [3]. In addition, the search for both safe and efficacious pharmacological therapies to treat obesity has proven difficult. For example, serotonin reuptake inhibitors were found to have serious cardiopulmonary side effects that limited their usage [3]. Cannabinoid type 1 receptor antagonists appeared to hold promise as effective weight loss medications without adverse cardiovascular-related events, but these drugs caused severe psychiatric side effects that precluded their usage [3]. This stresses the need to find efficacious pharmacological interventions with suitable safety profiles that both support weight loss and prevent debilitating chronic conditions that diminish life span.

Insufficient feeding can be equally deleterious. This is evidenced by the wide array of medical complications that arise with the self-imposed feeding restriction that defines the eating disorder anorexia nervosa (AN) [4]. This "relentless pursuit of thinness" has the highest mortality rate of any psychiatric illness [4], and there is an urgent need to find therapies that improve outcomes. AN is often accompanied by other psychiatric illness, including mood, anxiety and substance use disorders, and comorbidity is present in about $50 \%$ of all adolescents with AN [4]. Such comorbidity dictates the types of medications these patients receive. While use of antidepressants and antipsychotics can improve psychiatric symptoms, they fail to restore body weight [4]. As with obesity, finding efficacious pharmacotherapies for these patients has proven particularly difficult and has been limited by an incomplete understanding of how the brain regulates feeding. Thus, there is a crucial need to elucidate the neural signals that regulate feeding to direct discovery of interventions to treat eating disorders.

Neuropeptides have emerged as important regulators of body weight, with some promoting feeding (orexigenic) and others suppressing it (anorexigenic). The field has learned much about orexigenic neuropeptides. Yet, many anorexigens are comparatively less well characterized, though they may hold particular therapeutic promise for treating body weight disorders. Recently there has been increasing attention directed at how the neuropeptide neurotensin (Nts) modifies body weight. Nts signaling appears to play a pivotal, yet still poorly understood, role in intestinal fat absorption [5], but pharmacological data suggest that Nts may act centrally to suppress feeding. This review will focus on the growing understanding of how Nts signals within the brain, its contribution to regulation of energy 
balance and how disruption of central Nts signaling may underlie disordered feeding and body weight in disease.

\section{Neurotensin (Nts) Structure and Expression Pattern}

Nts was first isolated from purified bovine hypothalamus by Carraway and Leeman.

Injecting the isolated peptide intravenously into rats led to the initial characterization of Nts as a powerful hypotensive agent, an inducer of vascular permeability and a regulator of intestinal and uterine contraction [6]. These data suggested that Nts may not strictly exist as a central neuropeptide. Indeed, Nts was subsequently found within epithelial cells of the stomach and intestine [7]. Cloning of the Nts gene revealed that it contains coding sequences for both Nts and the Nts-related peptide Neuromedin $\mathrm{N}$ and led to the discovery that it produces a 169 amino acid precursor protein (pro-neurotensin, [pro-Nts]), which has an $\mathrm{N}$ terminal signal sequence and is processed into both peptides [8]. Furthermore, two differentsized mRNA products, a $1.0 \mathrm{~kb}$ or $1.5 \mathrm{~kb}$ mRNA species, may be produced, and these mRNAs differ in their 3' untranslated regions. Both transcripts are present in approximately equal ratios throughout the brain; however, the $1.0 \mathrm{~kb}$ mRNA species is 10 times more prevalent than the $1.5 \mathrm{~kb}$ mRNA within the intestine [8], suggesting tissue-specific regulation and perhaps differential peptide functions in the brain and periphery. Pro-Nts is subsequently cleaved by prohormone convertases to produce Neuromedin $\mathrm{N}$ and the Nts tridecapeptide (Glu-Leu-Tyr-Glu-Asn-Lys-Pro-Arg-Arg-Pro-Tyr-Ile-Leu-OH) [9]. Intriguingly, a truncated form of Nts (Nts 8-13) has superior Nts Receptor binding affinity compared to the full-length peptide, and this fragment is often used for in vitro studies of Nts action [9].

Nts is produced centrally and peripherally, but these pools of Nts are thought to mediate distinct actions. The abundant amount of Nts peptide found within the plasma may originate from the adrenal gland [10] and from the subset of intestinal enteroendocrine cells termed $\mathrm{N}-$ Cells [11]. Central vs. systemic administration of Nts produces different physiological responses. For instance, with intracisternal administration (a method of direct infusion into the subarachnoid space that allows drugs to bypass the blood-brain barrier), Nts induces antinociceptive and hypothermic effects. By contrast, intravenous (systemic) administration fails to produce either of these responses and, in fact, has been shown to result in elevated body temperature [12]. Intestinal Nts has recently been shown to be necessary for fat absorption via yet to be established mechanisms [5]. Circulating Nts levels are increased after bariatric surgery and weight loss, raising the possibility that Nts exerts some peripheral regulation of body weight [13]. Though the differential effects of central vs. peripheral Nts administration have led to the consensus that the blood-brain barrier is impermeable to Nts, new data suggests that there is some Nts transport to and from the brain [14]. This is further supported by the fact that peripheral Nts can activate brainstem structures in vagotomized mice and can induce gene expression of the anorectic peptide POMC within the arcuate nucleus of the hypothalamus [15]. However, given that the doses of Nts used in this study resulted in supraphysiological concentrations of circulating Nts [15], and given that Nts has a relatively short half-life in the blood [14], it is likely that central actions of Nts are primarily mediated via Nts produced within the brain. 
Immunohistochemical labeling of the specific brain cells that express Nts requires pretreatment with the axonal transport-inhibitor colchicine, and this necessity has complicated detection and subsequent study of these populations. Without colchicine treatment, Nts immunolabeling identifies Nts fibers while failing to detect the Nts-containing cell bodies of origin. Table 1 summarizes the reports of colchicine-mediated Nts-immunoreactive cell bodies and fibers in the rat brain, which are present within specific nuclei ranging from the hindbrain to the forebrain [16-21]. Many brain regions contain Nts cell bodies as well as fibers, which may signify Nts neurons that project locally to regulate adjacent cells. In some cases, however, Nts fibers are observed in regions that lack cell bodies. These may be axons of passage, or may identify terminal projection sites where Nts is released. Most of the sites with immunolabeled Nts cell bodies are consistent with the distribution of Nts neurons identified via in situ hybridization (ISH), as reported in the Allen Brain Atlas [22]. Both of these methods indicate substantial populations within the septal nuclei, preoptic area (POA), bed nucleus of the stria terminalis (BST), central amygdala (CeA), lateral hypothalamic area (LHA), parabrachial area (PB) and the nucleus of the solitary tract (NTS). An important species difference, however, is noted within the ventral tegmental area (VTA). Rats have a large population of VTA Nts neurons, most of which also contain dopamine (DA), but mice have very few VTA Nts cells [22]. In the rat, VTA Nts neurons also co-express the satietyinducing neuropeptide cholecystokinin (CCK), which suppresses feeding and elicits similar effects to intracerebroventricular (ICV) Nts treatment, including hypothermia, antinociception and neuroleptic-like activity [23]. Thus, while there is ample evidence to suggest that VTA Nts neurons directly overlap with anorectic and DAergic mechanisms to modify feeding in the rat, this differs in mice. Given the important role of DA neurons in feeding and body weight [24], the species differences in VTA Nts expression suggest very different mechanisms for Nts to modify DA signaling and behavior in rats and mice. Thus, investigators should use caution when studying the Nts system and interpreting results from different rodent models.

\section{Central Neurotensin Receptors (NtsRs)}

Nts binds brain and gut tissue [9], which is primarily mediated via Neurotensin Receptor 1 (NtsR1) and Neurotensin Receptor 2 (NtsR2) [25]. Although the NtsR1 and NtsR2 isoforms share $64 \%$ sequence homology, they differ in binding properties, expression and function. NtsR1 has a much higher affinity for Nts $\left(K_{d}=0.3 \mathrm{nM}\right)$ compared to NtsR2 $\left(K_{d} 2-4 n M\right)$, but only the NtsR2 isoform binds levocabastine (a Histamine H1 receptor antagonist with no known Nts-analogous effects) $[9,25,26]$. NtsR1 and NtsR2 are both G protein-coupled receptors and engage second messenger systems, though the exact system seems to depend on cell type [25]. Indeed, NtsR1 and NtsR2 are differentially expressed within the brain: NtsR2 expression was identified in both neurons and glia, but NtsR1 is found only in neurons $[27,28]$. Intriguingly, experimental brain injury increases the number of NtsR2expressing astrocytes and NtsR2 mRNA, suggesting a role for NtsR2 in the inflammatory response [27], though, this has yet to be fully understood. Recently, a third Nts receptor has been reported, Neurotensin Receptor 3 (NtsR3), which is identical to the previously identified sortilin protein [29]. NtsR3/sortilin is a single transmembrane receptor involved in membrane trafficking of ligands [29]. The N-glycosylated form of NtsR3/sortilin that resides 
on the plasma membrane internalizes upon Nts binding. Conversely, intracellular NtsR3/ sortilin is recruited to the plasma membrane as a result of Nts binding. Together, these data suggest that NtsR3/sortilin may be involved in turnover of the Nts peptide [29]. However, since no data exists linking NtsR3 to the central regulation of energy balance, the remainder of this review will primarily focus on the NtsR1 and NtsR2 isoforms that have been explored in regulation of body weight.

Nts binding can be detected throughout the entire rostral-caudal axis of the brain, with enrichment in some specific regions. Cloning of the three Nts receptor isoforms and development of ISH probes enabled more precise assessment of receptor localization, which has primarily been investigated within the rat brain [30-35]. Interestingly, NtsR1 is broadly expressed throughout the rat brain during gestation, perhaps suggesting that it contributes to the formation of neural circuits. However, since NtsR1 expression is more restricted within adults, it likely exerts more specified signaling roles in the mature brain [36]. This differential expression of NtsR1 over life span may account for the fact that transgenic $\mathrm{NtsR} 1{ }^{\mathrm{Cre}}$-reporter mice bred to Cre-inducible reporter strains identify numerous "NtsR1" cortical pyramidal cells within layer 6, even though ISH suggests that these cells do not actively express NtsR1 in the adult brain [22]. Presumably, the burst of early NtsR1 and Cre expression during development causes recombination and permanent cell labeling, even in cells that no longer express NtsR1. By contrast, NtsR2 expression is modest during development but increases over life span [9]. The distribution of NtsR isoforms reported in the adult rat brain via ISH or immunolabeling are summarized in Table 2, but functional studies (e.g. site-specific injections) suggest additional sites of NtsR expression. A number of brain regions contain Nts fibers (Table 1) and NtsRs (Table 2), indicating places where Nts is endogenously released and can engage NtsR isoforms. Such sites include the suprachiasmatic nucleus, SN, VTA, BST, and CeA. Both NtsR1 and NtsR2 isoforms are robustly expressed within the SN and VTA [32], and are also detected within the globus pallidus, BST, substantia innominata, suprachiasmatic nucleus, habenula, CeA, arcuate nucleus, subiculum and the zona incerta [32]. However, Table 2 also identifies regional differences in the distribution of NtsR1 and NtsR2, hinting that they do not exert completely overlapping functions. Additionally, while NtsR2 ISH expression was identified in cells with architecture resembling either neurons or glia [27], this was not the case for NtsR1, which was found only on cells with neuronal morphology. Interestingly, stab-wound lesions in rat brain significantly increase NtsR2-expressing astrocytes and NtsR2 mRNA, suggesting that NtsR2 may be predominantly astrocytic and may play a role in the inflammatory response after brain injury [27]. The similar overlap of NtsR3/sortilin expression with that of NtsR2 suggests that NtsR3/sortilin is also predominantly expressed on glia [33]. Subsequent development of $\mathrm{NtsR} 1^{\mathrm{Cre}}$ and $\mathrm{NtsR} 2^{\mathrm{Cre}}$ mice, which permitted labeling of these cells via Cre-inducible reporter protein expression, confirmed that most NtsR2-expressing cells coexpress the astrocyte marker S100 and are broadly distributed throughout the brain [28]. Additionally, consistent with NtsR1 ISH in the rat brain, these models revealed that mouse NtsR1 is confined to neurons, including a particularly dense population of DA-containing NtsR1 neurons found within the VTA [22,28,37]. Going forward, use of these mouse models will be helpful to visualize and selectively test the function of specific populations of NtsR1and NtsR2-expressing cells. 


\section{Physiology Regulated By Central Nts Signaling}

To date, pharmacological tools and genetic reagents have primarily been used to study how Nts functions via NtsR activation. Such pharmacological tools include the inhibitor SR142948A, which non-specifically antagonizes both NtsR1 and NtsR2, and SR48692, which selectively antagonizes NtsR1. These antagonists have been particularly useful in distinguishing physiology regulated via NtsR1 vs. NtsR2. In addition to the biological agonist levocabastine (which acts as an agonist of NtsR2 but not NtsR1), many NtsR1- or NtsR2-biased agonists are in development. Such agonists are being used to dissect the physiological effects engendered by each receptor isoform, with the long-term goal of modifying isoform-specific physiology for health benefits [38,39]. Additionally, different lines of NtsR1 and NtsR2 knockout mice have been generated [40-42]; however, differences in the genetic design or background of these strains may account for some of the conflicting physiology attributed to NtsR1 or NtsR2. For example, Table 3 compares the phenotypes between different lines of NtsR1 knockout mice [37,40-45]. Use of these mouse and pharmacological reagents has, however, provided some consensus on the role of central Nts via NtsR1 vs. NtsR2 in regulating analgesia, blood pressure, body temperature, locomotor activity, drug addiction, drinking and feeding/body weight. The physiologic effects of central Nts vs. site-specific Nts are depicted in Figure 1 and Table 4 [6,41,46-63], and are briefly described below.

\section{Analgesia}

Central administration of Nts or Nts agonists suppresses pain, and most evidence supports a primary role for NtsR2 in Nts-mediated analgesia. For example, Nts-mediated analgesia is blunted by the nonspecific NtsR antagonist SR142948A, but not the NtsR1-specific antagonist [9]. Nts-mediated analgesia is largely intact in NtsR1 knockout mice, but mice lacking NtsR2 have impaired thermal nociception [40-42]. Furthermore, NtsR2 selective agonists, including levocabastine, diminish a variety of pain responses in similar fashion to morphine [39], thus spurring interest in developing selective NtsR2 ligands to provide analgesia without addictive properties/dependence [39]. However, NtsR1 may also mediate certain aspects of pain signaling [64], and, hence, non-specific Nts agonists potentially hold promise for treatment of chronic pain.

\section{Blood Pressure}

Treatment with Nts causes a sustained decrease in blood pressure [6,46], which is thought to be mediated via NtsR1 [11] and may result from Nts action within the NTS [52]. Systemic treatment of rhesus monkeys with a brain penetrant Nts analog (NT69L) also induced hypotensive effects that precluded escalated dosing [65]. While this vasodepressor response dampened enthusiasm for potential clinical use of systemic Nts agonists, it remains possible that targeting certain NtsR-expressing populations within the brain might be useful to bias for specific Nts effects while bypassing hypotensive side effects. For example, since NtsR2 is not implicated in Nts-mediated hypotension, NtsR2-specific agonists may avoid any undesirable effects on blood pressure [11]. Similarly, the discovery that at least some NtsR1 forms heterodimer complexes with other receptors, such as DA receptor 2 (D2R), suggests that medical compounds targeting particular heterodimers might be useful for directing 
treatment to specific NtsR1 populations, while also circumventing the hypotensive effects mediated via hindbrain NtsR1 populations [66].

\section{Body Temperature}

Central Nts signaling via NtsR1 causes hypothermia in rodents [67]. Since mice lacking NtsR1 or rodents treated with NtsR2-specific analogs do not exhibit Nts-induced hypothermic responses, NtsR2-specified agents may have promise for use in clinical pain management while at the same time circumventing hypothermic side effects [39,41]. The precise NtsR1 neurons that mediate control of body temperature have yet to be established, but their molecular signature may provide insight into designing approaches for Nts agonists so as to avoid undesired hypothermic side effects. On the other hand, given that Ntsmediated hypothermia is protective in experimental brain injury models, selectively targeting NtsR1 neurons providing this action might be useful in treating stroke or other brain injury.

\section{Locomotor Activity}

Nts either promotes or suppresses locomotor activity depending on the site of action. Systemic, intracisternal and ICV Nts [48] or NtsR1 agonist treatment decreases psychostimulant-induced locomotor activity, which is mediated, at least in part, via NtsR1 in the nucleus accumbens (NAc) $[68,69]$. Conversely, infusion of Nts into the VTA evokes an increase in baseline and psychostimulant-induced locomotor activity $[55,56]$. The differential response to the administration of Nts within the VTA vs. globally throughout the CNS may be due to the cellular location of NtsRs. For example, intra-VTA Nts directly regulates NtsR1 and DA-expressing soma, which release DA to the NAc to modify motivated behaviors, including promoting goal-directed movement [28]. In contrast, the NAc contains D2R/NtsR1 hetero-complexes on glutamate terminals [70]; Nts acting at these receptors increases glutamate transmission, which in turn activates postsynaptic medium spiny GABA neurons. Additionally, some striatal GABA neurons may express D2R/NtsR1 complexes, permitting their direct activation. In either case, Nts in the NAc potentiates NAc GABA signaling [63,70,71], which is generally thought to suppress DA release from NAc DA terminals and diminish DA-mediated locomotor activity [70]. NAc Nts may also promote striatopallidal GABA release that facilitates inhibitory modulation of motor thalamus projections to the motor cortex, thereby decreasing locomotor activity [70,72]. While this mechanism has yet to be fully tested, it could be relevant to disease pathogenesis. Indeed, enhancement of striatopallidal GABA transmission is observed in response to NAc Nts administration or treatment with antipsychotics, and could be a common mechanism via which they protect against the psychomotor aspects of schizophrenia [72-74]. Overall, the distinct sites of NtsR1 in the VTA (directly on DA neurons) vs. the NAc (on glutamate terminals or GABA neurons) may explain why Nts in the VTA increases NAc DA release and locomotor activity while Nts in the NAc decreases DA release and locomotor activity. Since systemic Nts agonism suppresses locomotor activity, Nts potentiation of GABAergic signaling in the NAc may override Nts-induced DA release from VTA DA neurons. Thus, use of Nts agonists to target specific brain regions could be useful for treating distinct diseases. For example, NAc Nts agonists may be useful to suppress excessive psychomotor symptoms of schizophrenia, while targeting Nts signaling to the VTA may enhance voluntary exercise, which would be useful to support weight loss $[28,75]$. 
Studies of NtsR1 knockout mice support a role for NtsR1 in regulating normal locomotor activity, although, differences in study design may have masked its importance in some cases. For example, mice lacking NtsR1 have negligible novel environment-induced locomotor activity [41] but exhibit higher baseline and psychostimulant-induced locomotor activity compared to controls when allowed to acclimate to assessment chambers $[37,43,44]$. Since NtsR1 knockout mice have a mild anxiety phenotype [76], the presentation of a novel environment may represent a mild stress that initially obfuscates the hyperlocomotor phenotype of these mice. NtsR1 knockout mice also exhibit increased psychostimulantinduced striatal DA release [44], which is hypothesized to enhance striatal D2R transmission and reduce striatopallidal GABA release [72]. As mentioned above, striatopallidal GABA may be important for restraint of motor cortex activity [72]. Thus, loss of NtsR1 may reduce striatal GABA release with psychostimulant administration, ultimately contributing to the hyperactive behavior observed in NtsR1-deficient mice. Similarly, psychostimulanttreatment elicits a hyperdopaminergic response in schizophrenia patients, and the degree of DA release correlates with positive symptoms. These parallels have led to the use of NtsR1 knockout mice as an animal model of schizophrenia, particularly for psychomotor measures.

\section{Drug Addiction}

Since Nts modulates the mesolimbic DA system that governs motivated intake of natural rewards (food, water), as well as pharmacological rewards (drugs of abuse), Nts may contribute to addiction. To date, Nts has primarily been studied in regulating the intake and effects of psychostimulants, including cocaine, amphetamine and nicotine [70,77-83]. As with other Nts-mediated physiology, the effects of Nts with regard to drug addiction depends upon site of action. Nts administration within the VTA mimics some effects of psychostimulant treatment, including promoting self-administration, hyperactivity and DA release to the NAc, as well as generating a conditioned place preference and locomotor sensitization $[56,70,73]$. Conversely, Nts in the NAc abrogates amphetamine-induced locomotion as well as "rewarding" VTA electrical self-stimulation [73,84]. At face value, these findings suggest diverging roles for Nts to promote psychostimulant reward via the VTA, or to suppress it via the NAc. However, addiction is a complex and incompletely understood process, often producing different acute and chronic adaptations to neural circuitry that have yet to be disentangled. The role of Nts in addiction is similarly complex, such that Nts-NtsR1 signaling has been contradictorily implicated in promoting drug abuse as well as in attenuating it $[70,73,82,83]$. Thus, while Nts is well established to engage DA signaling systems that contribute to drug intake, there is currently no consensus view on how Nts modifies the system to regulate drug seeking or addiction. Further work is needed to dissect the acute and chronic roles of Nts in drug seeking and reinstatement, and this line of research holds promise to identify novel therapeutic interventions to treat addiction.

\section{Drinking}

Central infusion of Nts or $\mathrm{Nts}_{8-13}$ in water-deprived rats evokes significant increases in water consumption above saline-infused controls [49]. There is also data to suggest a sitespecific role for physiological Nts in drinking behavior, as ingestion of hypertonic saline upregulates Nts mRNA in a specific population of neurons within the LHA [85]. Since the LHA receives afferents from the medial preoptic area (MPO) and subfornical organ, two 
brain areas that relay changes in blood osmolality to other regions of the brain [86], it is tempting to speculate that LHA Nts neurons might coordinate sensation of osmotic need with Nts-mediated drinking behavior. Indeed, experimental activation of LHA Nts neurons promotes voracious water intake [87]. Nts has also been shown to amplify the effect of hypertonic saline solution on the firing rate and depolarization of supraoptic magnocellular neurosecretory cells, which act as osmosensors and respond to hyperosmotic extracellular fluid by permitting vasopressin release from the neurohypophysis [88]. Thus, Nts might promote water intake and also facilitate water retention via vasopressin release, the timing of which closely mirrors the osmotic threshold for the sensation of thirst. It remains unclear whether any specific NtsR isoform governs general drinking behavior, but both NtsR1 and NtsR2 have been implicated in mediating ethanol consumption and its effects [11].

\section{Feeding and Body Weight}

Systemic Nts treatment mildly suppresses homeostatic feeding in mice, particularly during the dark phase when they are most hungry and consume the bulk of their daily food. Repeated systemic Nts treatments did not result in significant long-term suppression of feeding [48]; however, this may be due to the fact that the normal weight animals in this study had minimal body fat to lose, and, hence, any weight loss presumably caused a homeostatic counter-response to ensure sufficient energy balance for survival. Nts may exert a stronger anorectic effect in the face of increased motivation. Indeed, in rodents that are hungry, due to either fasting [43,50] or due to having an increased appetitive drive that accompanies obesity [67], central Nts or NtsR1 agonists restrain feeding. Pharmacological data and genetic knockout mouse studies indicate NtsR1 as the principal mediator of the anorectic action of Nts [41,43], and this is further bolstered by the fact that Nts-induced suppression of feeding is absent in mice lacking NtsR1[87]. Studies of different strains of NtsR1 knockout mice, however, have produced differing conclusions about the necessity of NtsR1 for regulation of homeostatic feeding and body weight (Table 3). Some strains of NtsR1 knockout mice exhibit mild hyperphagia for chow that leads to modestly increased body weight as mice age as well as increased basal body temperature [41,43]. Given the mild stress and hyperlocomotor phenotype of mice lacking NtsR1, it is possible that these mice might eat modestly more food to support their elevated physical activity. By contrast, the commercially available strain of NtsR1 knockout mice from Jackson Labs (originally developed by Deltagen, USA) display opposing consumatory behaviors: they eat less chow than littermate controls, but overconsume palatable (e.g. rewarding) high fat/high sucrose food and exhibit increased sucrose-preference, both of which promote weight gain [37]. These findings imply that while NtsR1 plays a subtle role in the homeostatic maintenance of food intake [37], it is perhaps more crucial for restraining motivated consumption of tasty, calorically dense foods [87]. Since the obesity epidemic stems, in part, from overconsumption of calorie-dense foods, modulation of the Nts/NtsR1 system may hold promise to restrain food intake and support healthy body weight.

Anorectic leptin signaling also depends, in part, on Nts action via NtsR1, and these systems converge to support weight loss. Both central Nts and leptin reduce fasting-induced refeeding in control mice, but these signals fail to suppress feeding in mice lacking NtsR1 [43] or in rats pre-treated with reagents to block NtsR1 signaling [89], indicating that Nts/NtsR1 
signaling may be required for leptin-mediated anorexia. Acute leptin treatment elevates hypothalamic Nts expression, and the absence of this effect in pair-fed control rats indicates that this expression is specifically induced by leptin (not just weight loss) [90]. However, elevated Nts expression and feeding restraint both diminish after chronic leptin treatment [89], which may replicate the hyperleptinemic state of obese individuals who seemingly no longer respond to the appetite-suppressing effects of the hormone. This fluctuation in Nts gene expression is similar to the change in hypothalamic POMC expression, and reduced expression of these two anorectic neuropeptides may partly explain the acquired "leptin resistance" that occurs in obesity [89]. Overall, the functional overlap of the Nts and leptin systems indicate that they must also overlap anatomically and that there might be sitespecified Nts/NtsR1 circuits that regulate feeding and body weight.

\section{Specific Nts Circuits Implicated In Feeding}

Nts injection into select regions of the brain suppresses feeding [53,58-60] (described in Fig. 1 and Table 4). Notably, Nts does not alter feeding if infused into the NAc, where it is known to suppress psychomotor responses [59,62]; thus, Nts suppresses feeding and locomotor activity via distinct circuits, supporting the idea that it may be possible to differentially regulate these actions with application of Nts agonists in a site-specific manner. For example, Nts acts within the paraventricular hypothalamic nucleus (PVN) to suppress feeding [53] and regulate corticotropin-releasing hormone (CRH) expression and release, though it is not clear if $\mathrm{CRH}$ is required for the anorexia elicited by Nts at this site [91]. Nts neurons within the dorsomedial hypothalamus project to the PVN, and leptin activation of these neurons may promote endogenous Nts release to the PVN [92]. Given that leptin also induces expression of Nts [90] and CRH [93], and that at least some of its anorectic effect is dependent on Nts and CRH signaling [37,93], it is possible that leptin, Nts and CRH act in concert to suppress feeding at the level of the PVN. Nts may also act within the ventromedial hypothalamic nucleus (VMH) to curb unnecessary food intake, since obese rats, but not their lean counterparts, display a 50\% reduction in VMH Nts with fasting [94]; the mechanism by which this occurs, however, is unknown. Nts also suppresses feeding when injected into the NTS [53]. Endogenous Nts may be released from local Ntsexpressing NTS neurons; yet, the resident Nts neurons are not regulated by anorectic signals, so it remains unclear if and how they mediate anorectic effects [95,96]. Additionally, Nts may exert its anorectic effect via the histamine signaling pathway, since pharmacological or genetic disruption of the $\mathrm{H}_{1}$ receptor blunts Nts-mediated suppression of feeding [97]. These few studies hint at functional sites and mechanisms by which Nts exerts anorexia, but more work is necessary to fully appreciate their contributions.

By comparison, there is a far greater understanding of how Nts acts in the VTA, where it engages the mesolimbic DA system to suppress feeding. The VTA is primarily composed of DA-producing neurons that release DA into the ventral striatum/NAc (the mesolimbic system) or the prefrontal cortex (the mesocortical system). Nts administration specifically into the VTA also induces DA release into the ventral striatum, increases locomotor activity [56] and suppresses food intake in the contexts of either fasting or training that heightens the motivation to consume food [58,57]. These data suggest that Nts may selectively engage the mesolimbic DA circuit, and the motivated behaviors it regulates, more so than the 
mesocortical DA circuit. Recent anatomical evidence supports this idea, since NtsR1 is expressed on a subset of DA neurons within the VTA that specifically project to the ventral striatum (Fig. 2) [28,37]. Nts acts via NtsR1 to increase the activation of VTA DA neurons and elicit DA release into the NAc [56,98], where DA release is known to regulate both feeding and locomotor activity. Very few VTA DA neurons express NtsR2; hence, NtsR1 is the primary receptor isoform by which Nts directly modifies the activity of VTA DA neurons [28]. However, there are many NtsR2-expressing astrocytes within the VTA, so it is entirely possible that Nts might indirectly alter DA signaling through signaling in astrocytes [28]. Nts acting directly via VTA NtsR1 increases the activity of DA neurons via several mechanisms, including attenuating D2R auto-inhibition via NtsR1/D2R hetero-complexes, inhibiting IPSCs induced via D2R and $\mathrm{GABA}_{\mathrm{B}}$ receptors and activating a nonselective inward cation current [99]. However, the source of Nts input to the VTA that activates DA neurons and mediates anorectic actions via this circuit has yet to be defined. Rats have Ntscontaining soma within the VTA that may release DA locally, but the paucity of Nts soma in mice suggests that VTA-acting Nts must originate from other regions $[16,18,22]$.

Nts neurons within the lateral hypothalamic area (LHA) are a potential source of the Nts that mediates anorectic actions via the VTA, and the many cues that induce anorectic LHA Nts neuron signaling are depicted in Figure 2. LHA Nts neurons densely project to the VTA and SN [37,75], and the overlap of LHA Nts neurons with known anorectic systems suggests that the LHA Nts $\rightarrow$ VTA circuit may contribute to Nts-mediated anorexia. Indeed, 15-30\% of all LHA Nts neurons co-express the long form of the leptin receptor (LepRb) [100,101], functionally linking the anorectic Nts and leptin systems. While LepRb and Nts are separately expressed in other sites throughout the brain, their expression only overlaps within the LHA, indicating that $\mathrm{Nts}^{\mathrm{LepRb}}$ neurons are the unique joint mediators of $\mathrm{Nts}$ and leptin action. If this is true, then disruption of either leptin or Nts signaling via these neurons should disrupt VTA DA action and physiology. Indeed, loss of leptin signaling via the $\mathrm{Nts}^{\mathrm{LepRb}}$ neurons mildly increases feeding at early ages, diminishes locomotor activity and disrupts mesolimbic DA signaling, leading to increased adiposity and weight gain [100]. Similarly, the anorectic effects of circulating leptin are abrogated in the face of systemic NtsR1 antagonism or in NtsR1 knockout mice [43,89], and specific leptin-mediated activation of the LHA Nts ${ }^{\mathrm{LepRb}}$ neurons in mice lacking NtsR1 caused them to eat more food, decreased VTA tyrosine hydroxylase expression and increased body weight [37]. Leptin-deficient $o b / o b$ mice also have diminished VTA tyrosine hydroxylase and exhibit hyperphagia, both of which are resolved with leptin treatment [100]. This effect of leptin treatment is likely mediated, at least in part, via the leptin-sensitive $\mathrm{Nts}^{\mathrm{LepRb}}$ neurons that engage VTA NtsR1 neurons. Thus, at least some portion of the anorectic function of leptin and VTA Nts signaling is mediated via LHA Nts ${ }^{\text {LepRb }}$ neurons and NtsR1-expressing neurons, presumably those in the VTA. However, given that most Nts neurons in the LHA do not express LepRb, there may be other mechanisms via which LHA Nts neurons coordinate anorectic actions via the VTA or other projection sites. Activating the general population of LHA Nts neurons, the majority of which do not express LepRb, induces Nts release to the VTA as well as locomotor activity and metabolic rate, but suppresses feeding leading to weight loss [75,87]. Since antagonizing NtsR1 or D1R blocks the feeding suppression elicited with LHA Nts neuron activation, it is likely that there is a functional 
link of LHA Nts neurons with Nts- and mesolimbic-dependent control of feeding behaviors [87].

LHA Nts neurons may suppress feeding via another mechanism: local projections onto neurons expressing Orexin/Hypocretin (OX). OX neurons promote food intake and locomotor activity to support arousal [102], hence, acute inhibition of OX neurons may suppress feeding behavior. Leptin or experimental activation of LHA Nts neurons hyperpolarizes OX neurons, although this occurs independent of Nts signaling [102]. Given that adult OX neurons do not express NtsR1 [37], and that NtsR2 is primarily expressed by glia [27,28], any Nts released locally into the LHA is unlikely to directly regulate OX neurons. Nts could presumably act via NtsR2-expressing glia to indirectly modify the activity of OX neurons. Alternately, LHA Nts neurons may release other signals that inhibit OX neurons, such as galanin [102]. While Nts released from LHA Nts neurons may not directly suppress the activity of OX neurons, the interconnectivity of these neuronal populations is important for normal regulation of feeding and body weight. For example, mice genetically lacking LepRb in LHA Nts ${ }^{\mathrm{LepRb}}$ neurons do not exhibit appropriate regulation of OX neuronal activity in response to fasting, leptin or ghrelin, and, hence, cannot adapt to alter feeding in response to changes in peripheral energy balance $[100,101]$.

LHA Nts neurons are also regulated by other signals that convey energy status and lead to changes in feeding accordingly. For example, treatment with lipopolysaccharide (LPS) leads to the activation of LHA Nts neurons, which in turn inhibit downstream OX neurons [103]. Inflammatory activation of the LHA Nts $\rightarrow$ OX circuit may serve to suppress OX-mediated arousal, producing lethargy necessary to minimize energy expenditure when mammals are sick. LHA Nts neurons are also activated during dehydration-anorexia, a state in which dehydrated animals cease eating until they have restored serum osmolality via drinking water [85]. In rats, dehydration-anorexia causes increased synthesis of Nts and CRH within the same LHA neurons [85]. These data suggest LHA Nts neurons may coordinate the need for water and food but prioritize water seeking above feeding until normal cellular osmolality is restored. While LHA Nts neurons may be activated by diverse physiologic cues (leptin, inflammatory cues, dehydration), all of these signals are known to suppress feeding, consistent with the central role of Nts as an anorectic peptide.

Much remains to be understood concerning precisely how Nts neurons control feeding, but these collective data confirm that central Nts signaling is important for the normal physiological processes of feeding and energy balance. It therefore stands to reason that any disruptions of Nts signaling present in disease states will also derange feeding behavior and body weight. Altered Nts signaling is specifically implicated in the pathophysiology of schizophrenia, Parkinson's disease, eating disorders and obesity, and hence, may contribute to the altered feeding and energy balance associated with these diseases.

\section{Nts and Schizophrenia}

Hyperactivity of the mesolimbic DA system and resulting elevations in striatal DA contribute to psychosis, a defining feature of schizophrenia [11,71]. Since Nts attenuates DA signaling via actions in the NAc, loss of Nts action via this site might promote a 
hyperdopaminergic state that contributes to the pathogenesis of schizophrenia. Indeed, Nts is reduced in the cerebrospinal fluid (CSF) of untreated schizophrenic patients, and Nts levels correlate with disease severity, such that individuals with higher drug-free Nts levels have with fewer behavioral deficits [71]. By contrast, treatment with typical and atypical antipsychotic drugs elevates striatal Nts [71] and blunts DA-mediated locomotion similar to that evoked by administration of Nts into the NAc. Nts may act via NtsR1 expressed on either NAc glutamatergic terminals or cell bodies and dendrites of NAc medium spiny GABA neurons [70,71], where Nts action at NtsR1-D2R heterodimers might support GABA release and, consequently, inhibit striatal DA release [71]. Similar to antipsychotics, Nts in the NAc may also increase striatopallidal GABA, which is thought to restore thalamocortical glutamatergic signaling and attenuate psychomotor effects [74]. Thus, Nts and antipsychotics may act similarly at the level of the NAc to suppress excessive DA-signaling and hyperdopaminergic psychosis.

Given that Nts action via NtsR1 may be required for normal DAergic tone, loss of action via NtsR1 might promote development of schizophrenia. NtsR1 knockout mice have therefore been studied as a potential model for this disease. Indeed, NtsR1 knockout mice exhibit excess striatal DA, typical of human schizophrenia, as well as altered striatal expression of $\mathrm{D} 1 \mathrm{R}$ and D2R [44]. A possible explanation for these effects is that NAc NtsR1 is necessary to restrain striatal DA release (via mechanisms discussed earlier). If this is true, then loss of NtsR1 might lead to unchecked striatal DA signaling that promotes psychomotor dysfunction. Yet, NtsR1 knockout mice also lack NtsR1-expression on the VTA DA neurons that release DA to the NAc, which would be expected to result in diminished DA signaling. Given that Nts promotes distinct actions via the NAc and VTA, it is possible that loss of NtsNtsR1 action also has site-specific effects. Hence, loss of Nts-NtsR1 action via the NAc may be the primary driver of the hyperdopaminergic state characteristic of schizophrenia, whereas loss of NtsR1-driven VTA DA signaling might not be pathogenetic. Such mechanisms have yet to be fully tested but could explain the behavioral disruptions observed in NtsR1 knockout mice that are pathogenomic of schizophrenia, including increased psychostimulant-induced locomotor activity and avolition (e.g. a lack of motivation to do tasks that have an end goal) [11]. Polymorphisms in the NtsR1 gene have also been identified in human individuals with schizophrenia; however, it remains unknown whether these polymorphisms result in altered Nts binding properties or function [71]. Thus, while there is some data linking genetic disruption of Nts signaling with schizophrenia, further work is required to determine whether it indeed contributes to disease onset.

Individuals with schizophrenia have a higher prevalence of obesity and type-2 diabetes compared to the general population, suggesting some pathogenetic overlap with the systems that control body weight [104]. Furthermore, some antipsychotic medications, particularly olanzapine and clozapine [104], promote weight gain, which can spur patient noncompliance in taking these medications and, as a result, relapse of the psychotic effects. Antipsychotics may contribute to weight gain via a number of mechanisms, some of which may be thwarted by Nts signaling. First, antipsychotics antagonize hypothalamic serotonin 5-HT2C and histamine $\mathrm{H}_{1}$ receptors, and antagonism of these two receptors induces feeding [105]. In contrast, Nts agonism of histamine $\mathrm{H}_{1}$ signaling is thought to contribute to its anorectic action [97]. Secondly, antipsychotics increase OX expression in rodents [106], 
which promotes arousal and feeding that may lead to weight gain. By contrast, Nts neurons inhibit OX neurons, thereby negating their feeding-promoting effects [102]. Thus, while Nts and antipsychotics behave similarly by suppressing DA-dependent locomotion, they exert opposing effects on regulation of food intake. Going forward, it will be important to assess whether Nts agonism may have efficacy for treating the psychomotor and metabolic symptoms of schizophrenia.

Antipsychotic-mediated antagonism of DA signaling and Nts action may mechanistically converge in their ability to modify the motivational salience of food (how much it is "wanted") but not its hedonic value (how much it is "liked") [107]. D2R antagonists such as raclopride decrease intra-accumbal DA and effort-related responding for palatable foods, but do not alter consumption of freely available standard chow. Similarly, Nts signaling more effectively suppresses fasting-induced or motivated feeding compared to homeostatic feeding [87]. Thus, D2R antagonism by antipsychotics may dampen the VTA DA-mediated "wanting" of highly pleasurable foods, but are unlikely to alter the "liking" of foods that is regulated via separate circuits. This is consistent with reports that schizophrenic patients on antipsychotics rate all foods types, including those deemed less-appetitive according to healthy controls, as having high hedonic value [108], and this food "liking" might potentiate their feeding and weight gain. Nts signaling is also required to suppress intake of highly palatable foods [37], and the VTA NtsR1 neurons that project to the NAc may be a common node by which Nts and antipsychotics modify motivated feeding behaviors. It is possible that Nts acting via VTA NtsR1/D2R hetero-receptor complexes might exert NtsR1-mediated anorectic actions while blocking D2Rmediated psychomotor effects, without antagonizing D2R-mediated feeding control. The recent report of bivalent compounds that selectively target these NtsR1-D2R hetero-complexes while biasing for NtsR1-mediated signaling suggests future potential to selectively target this system in schizophrenic patients [109], which would, perhaps, blunt associated psychomotor effects while restraining feeding. Since weight gain is a major reason for medication noncompliance among schizophrenic patients, such drugs could be a useful alternative to stand-alone antipsychotics that produce this and other undesirable side effects.

\section{Nts and Parkinson's Disease}

Parkinson's Disease (PD) is a neurodegenerative disorder characterized by the progressive loss of nigrostriatal DA neurons and is associated with symptoms of disordered movement, such as tremor, muscular rigidity, and bradykinesia. Many NtsR1-expressing neurons are found within the SN [30,31], and since approximately half co-express DA [37], there may be an overlapping mechanism for Nts and DA action in PD. This may explain why brains of PD patients have diminished nigrostriatal DA neurons along with decreased Nts binding and NtsR1 mRNA within the SN [110,111]. While PD is typically characterized by the motor impairments that ensue in later stages of the disease, pre-diagnostic PD patients display deviations in body weight [112]. The cause of altered energy balance may differ over the course of the disease. Initial body weight deviations in PD could result from disruptions in the DA-mediated regulation of feeding, as these changes are observable in PD patients prior to the development of motor symptoms [112]. During later stages of PD, the rigidity and tremor elevates patients' resting energy expenditure, which may exacerbate weight loss 
[112]. Curiously, non-medicated PD patients exhibit elevated plasma Nts compared to healthy controls and levodopa-treated PD patients [110,111], and the SN of PD patient brains have higher Nts levels [111]. This elevation in Nts may be compensatory and may reflect an Nts-driven enhancement of midbrain DAergic signaling to offset the diminished signaling resulting from loss of SN DA neurons. Based on this reasoning, Nts analogs could potentially be used as anti-Parkinsonian drugs to stimulate DA signaling via any remaining NtsR1-expressing SN DA neurons. Indeed, in rodent models of PD, Nts reduces muscular rigidity and tremor [111]. Use of NtsR1 antagonists have also been considered for use as therapeutic agents due to the fact that striatal Nts-NtsR1 signaling decreases striatal DA via suppression of D2R receptors. However, no improvement in motor symptoms was observed in PD patients receiving NtsR1 antagonists, though the study may have been underpowered to detect significant effects $[111,113]$. While Nts signaling is altered by PD, it is yet unknown whether it contributes to the development of the disease or whether it is simply a consequence of disrupted DA neurons.

\section{Nts and Eating Disorders}

The sexually dimorphic expression of Nts in the brain suggests that Nts signaling may contribute to the noted differences in feeding regulation between males and females, and, perhaps, to the pathogenesis of female-prevalent eating disorders. Nts/Neuromedin are expressed within the MPO and the anteroventral periventricular nucleus (AVPe), though females have 4 times the number of Nts-expressing cells in the AVPe compared to males [114]. Furthermore, estrogen promotes Nts gene expression in the MPO of female rodents $[115,116]$, and Nts expression levels fluctuate in accordance with plasma estradiol during the estrous cycle [114]. Given that central estradiol suppresses feeding in part via actions in the MPO [117] and that expression of Nts in this brain region is regulated by estradiol [115], the anorectic functions of estradiol and Nts may be mechanistically intertwined.

Furthermore, increases in levels of sex steroid hormones that occur during puberty, including estrogen, result in gene expression changes that promote development of eating disorders, such as anorexia nervosa (AN) and bulimia nervosa, in genetically predisposed individuals [118]. This is evidenced by twin studies showing that genetic effects on disordered eating increase throughout puberty, a time period in which ovarian hormones, like estradiol, drive developmental changes [118]. Alterations in gene transcription that result from elevated estradiol during puberty can moderate food intake, and disordered eating, assessed via the Minnesota Eating Behavior Survey (MEBS), correlates with plasma estradiol levels in females [118]. Together these data suggest that dysfunction of estrogen and Nts-mediated signaling may potentiate the development of eating disorders.

There are a number of Nts-influenced mechanisms implicated in appetite suppression that may contribute to development of eating disorders. For example, the parabrachial nucleus $(\mathrm{PB}) \rightarrow$ Central Amygdala (CeA) neural circuit has been elegantly tested and shown to coordinate anorexigenic signals with suppression of food intake [119]. Since some PB Nts neurons send fibers to the CeA, Nts might mediate some of the anorectic function of this circuit [120]. Amygdala dysfunction is specifically implicated in eating disorders, and given the dense Nts inputs to this region and the sizeable population of Nts neurons within the amygdala, altered amygdala Nts signaling could be a contributing factor. Indeed, the 
amygdala of non-recovered AN patients contains significantly reduced grey matter volume relative to weight-restored AN patients and healthy weight controls [121]. Additionally, estradiol heightens the anorectic response to the satiety cue CCK via a NTS $\rightarrow$ lateral PB $\rightarrow$ CeA circuit $[122,123]$. Since this pathway contains Nts projections and conveys degree of satiety in an estradiol-dependent manner, Nts may contribute to the pathogenesis of eating disorders. Additionally, Nts may exert central anorectic effects in part through Histamine $\mathrm{H}_{1} \mathrm{R}$ [97], which is expressed within the amygdala. Consistent with the female prevalence of eating disorders, females have higher histamine $\mathrm{H}_{1} \mathrm{R}$ densities compared to males, and females with the restricting subtype of AN have further elevated levels compared to normal weight female controls [124]. Thus, it is conceivable that Nts, which exerts its central anorectic effects in part through Histamine $\mathrm{H}_{1} \mathrm{R}$ [97], could elicit a greater degree of anorexia in both females and AN patients through this enhanced central histaminergic system. Additionally, plasma activity levels of prolyl endopeptidase are significantly lower in females with either the restricting or binging subtypes of AN and in females with bulimia nervosa compared to healthy controls [125]. Prolyl endopeptidases are known to degrade Nts, and their prevalence within the brain make these enzymes likely regulators of Nts levels. Thus, based on the likely low degradation of central Nts by prolyl endopeptidases and the measured increases in CNS histamine $\mathrm{H}_{1} \mathrm{R}$ densities in eating disorder patients, one might expect heightened Nts-mediated anorectic action in these individuals.

Nts signaling is well established to regulate the mesolimbic DA system, but this system is hyperactive in AN patients, especially upon viewing images of underweight women [126]. Hyperactivity of the ventral striatum has also been shown to occur in recovered AN patients in response to the taste of chocolate, a highly palatable substance [127]. This heightened salience to both highly palatable food as well as underweight stimuli may explain why these individuals exhibit restraint and avoidance behaviors with regard to food [127]. Aberrant DA signaling in the ventral striatum is likely in these patients, as increased D2/D3 R binding densities are present in the ventral striatum [126], and reduced levels of the DA metabolite Homovanillic acid (HVA) have been measured in the CSF of AN-recovered individuals [126]. Alterations in DA-based reward circuits are not surprising, as AN individuals are essentially addicted to food restriction and exercise [128]. This link between reduced food consumption and excessive exercise has been observed in the activity-based anorexia (ABA) model, in which rats that have a limited time to feed exhibit increases in wheel running activity [128]. This behavior has been attributed to food-anticipatory activity, which is the increased food-seeking behavior and, thus, increased activity that occurs when food access is limited [128]. Interestingly, when rats subjected to the ABA model are treated with a nonselective DA antagonist, activity levels are reduced, which is similarly observed in ad lib fed controls; however, food intake is increased only in the food-restricted rats [129]. Thus, one could argue that hyperactive Nts signaling to VTA DA neurons, driving DA release in the NAc, might contribute to the pathogenesis of AN. Given that intra-VTA Nts restrains feeding and increases locomotor activity, behaviors that become maladaptive in $\mathrm{AN}$, altered Nts regulation of VTA DA signaling could explain some of the core behavioral features of restrictive eating disorders.

Loss of Nts action may also promote a hyper-DAergic state that potentiates eating disorders. Mice lacking NtsR1 have a hyperactive DA system along with disrupted feeding and 
increased DA-mediated locomotor activity [37,44], features similar to human AN. Likewise, administration of the NtsR1 antagonist SR 48692 specifically to the striatum potentiates DAinduced hyperlocomotion and stereotypic behaviors [130], likely due to loss of the suppressive action of Nts on D2R signaling. One can reason, therefore, that striatal Nts is necessary to modulate and restrain the hyperlocomotor and stereotypy behaviors that striatal DA elicits. In this way, loss of Nts signaling within the striatum would be expected to contribute to the hyperlocomotor, stereotypic, and food anticipatory behaviors that are observed in rodent models and mimic core features of human AN. Loss of Nts or NtsR1 signaling may have face validity for human disease, as loss of function variants in multiple genes within the Nts signaling pathway have recently been found to be enriched in individuals with eating disorders [131]. Going forward it will be important to verify whether loss of function via the Nts system is a genetic risk factor that predisposes individuals to developing AN.

\section{Nts and Obesity}

Central Nts expression is diminished in obese rodents compared to normal weight controls, suggesting that loss of Nts signaling might contribute to pathogenesis of obesity [94,132135]. For instance, significant reductions in Nts concentration have been detected within the VMH of obese Zucker rats when fasted, whereas fasting did not diminish VMH Nts in lean counterparts [94]. In addition, Nts levels are specifically decreased within the LHA of rats fed a high-fat diet as well as mice that are obese due to genetic loss of leptin expression, emphasizing the potential overlap of signaling via $\mathrm{Nts}^{\mathrm{LepRb}}$ neurons for regulating feeding and body weight [94,132-134]. Based on these data, it has been hypothesized that enhancing Nts signaling might support weight loss in obesity. Indeed, 10 days of systemic treatment with brain-penetrant NtsR1 agonists curbs food intake and promotes weight loss in genetically obese rodents, including leptin-deficient $o b / o b$ mice [67] and LepRb-deficient Zucker rats [136]. Importantly, the appetite-suppressing effects of systemically-administered Nts agonist PD149163 persisted over the entire treatment period, while the initial hypothermia and suppressive locomotor effects were normalized by the end of the study. Unfortunately, the effect of sustained treatment on blood pressure was not reported [67]. At the least, these data suggest that sustained Nts agonism might support weight loss without long-term side effects on body temperature and metabolism.

Disruption of the DA system is linked with obesity; thus, modulating Nts systems engaging mesolimbic DA circuits might conceivably restore disrupted DA action to support weight loss. The precise nature of the DA system deficit in obesity has been debated, but one hypothesis suggests that diminished DA signaling promotes weight gain. In support of this, obese rodents exhibit reduced striatal and hypothalamic D2R binding, and obesity-prone rodents exhibit reduced D1R expression, low basal levels of DA within the NAc and diminished DA release to the striatum and prefrontal cortex [137]. Humans harboring the Taq1A polymorphism of the D2R gene also have reduced D2R binding sites [137], and, in general, striatal D2R binding density negatively correlates with BMI in obese persons [137]. Together, these data support a pathogenetic role for a hypo-functioning DA system in obesity. Thus, it is not hard to imagine that Nts agonists administered in the VTA, which 
have been demonstrated to elicit elevations in striatal DA, might be useful to normalize reduced DA signaling $[75,56]$.

Peripheral sources of Nts may also factor into the pathogenesis of obesity. Under normal circumstances, ingestion of food elevates Nts plasma levels [138], and while the majority of this peripheral pool of Nts does not access the brain, a limited amount may access some brain regions to exert anorectic feedback [15]. However, individuals who are obese due to lifestyle or Prader-Willi syndrome (a genetic disease characterized by severe hyperphagia and childhood obesity) have elevated circulating pro-Nts [5,139]. It is yet unclear whether the pro-Nts in these individuals is processed to the active form; hence, elevated levels of pro$\mathrm{Nts}$ might reflect diminished Nts function. Indeed, variants in the gene for carboxypeptidase $\mathrm{E}$ (an enzyme responsible for removal of Lys-Arg dibasic residues in the pro-Nts precursor), are significantly associated with BMI, and mice with nonfunctional carboxypeptidase E have impaired pro-Nts processing and reduced levels of mature Nts compared to controls [140]. Thus, future work will be required to determine whether low or elevated levels of mature, functional Nts correlate with likelihood of obesity. Persistently elevated circulating Nts levels, however, could represent a compensatory effort to enhance the minimal amount of circulatory Nts that reaches brain structures with a permissive or absent BBB, so as to mediate some anorectic function [139]. Consistent with this idea, Roux-en-Y Gastric Bypass surgery elevates plasma Nts levels relative to sham-operated rats, which contributes to their reduced food intake via an NtsR-dependent mechanism [15]. Peripheral Nts has been shown to increase neuronal activation in several brain regions implicated in the homeostatic regulation of food intake, including the arcuate nucleus, PVN, and NTS [15]. Thus, elevated peripheral Nts in gastric bypass patients may act at these feeding centers to promote reduced feeding. Vagal afferents may additionally be necessary for peripheral Nts to elicit a central anorectic effect [15]. Since morbidly obese individuals also exhibit increased levels of plasma Nts following gastric bypass surgery [13], this may be a beneficial adaptation to enhance some central Nts signaling and reduce appetite.

\section{Conclusion}

Central manipulation of Nts signaling may prove useful in treatment of a multitude of diseases. The Nts system has the potential to be a particularly convenient drug target for metabolic aspects of different diseases, as there are numerous Nts populations throughout the brain that regulate energy balance in different capacities, via different receptor and circuit mechanisms, and in different contexts. Thus, targeting specific Nts neuronal circuits

could potentially treat divergent conditions that disrupt weight, including obesity and AN. In order to determine if the discrete Nts circuits discussed in this review should be pursued as targets, more work is needed to assess exactly how these circuits alter feeding, locomotor activity, and metabolic rate to modify body weight. In addition, there are also robust Nts populations in regions, such as the $\mathrm{PB}$ and CeA, that have yet to be characterized but which may be important contributors to the regulation of appetite mediated via these sites. Going forward, there is thus need for additional investigation into the potential of $\mathrm{Nts}$ as a novel target to modify appetite and body weight, as well as to describe how the various Nts populations throughout the brain contribute to feeding and other aspects of Nts-mediated physiology. 


\section{Acknowledgments}

This scholarly work was supported by funding from the NIH to GML (R01-DK103808).

\section{References}

1. Budd GM, Peterson JA. The Obesity Epidemic. Part 1 : Understanding the Origins. 2014; 114:4046.

2. Afshin A, Forouzanfar MH, Reitsma MB, Sur P, Estep K, Lee A, Marczak L, Mokdad AH, MoradiLakeh M, Naghavi M, Salama JS, Vos T, Abate KH, Abbafati C, Ahmed MB, Al-Aly Z, Alkerwi A, Al-Raddadi R, Amare AT, Amberbir A, Amegah AK, Amini E, Amrock SM, Anjana RM, Ärnlöv J, Asayesh H, Banerjee A, Barac A, Baye E, Bennett DA, Beyene AS, Biadgilign S, Biryukov S, Bjertness E, Boneya DJ, Campos-Nonato I, Carrero JJ, Cecilio P, Cercy K, Ciobanu LG, Cornaby L, Damtew SA, Dandona L, Dandona R, Dharmaratne SD, Duncan BB, Eshrati B, Esteghamati A, Feigin VL, Fernandes JC, Fürst T, Gebrehiwot TT, Gold A, Gona PN, Goto A, Habtewold TD, Hadush KT, Hafezi-Nejad N, Hay SI, Horino M, Islami F, Kamal R, Kasaeian A, V Katikireddi S, Kengne AP, Kesavachandran CN, Khader YS, Khang Y-H, Khubchandani J, Kim D, Kim YJ, Kinfu Y, Kosen S, Ku T, Defo BK, Kumar GA, Larson HJ, Leinsalu M, Liang X, Lim SS, Liu P, Lopez AD, Lozano R, Majeed A, Malekzadeh R, Malta DC, Mazidi M, McAlinden C, McGarvey ST, Mengistu DT, Mensah GA, Mensink GBM, Mezgebe HB, Mirrakhimov EM, Mueller UO, Noubiap JJ, Obermeyer CM, Ogbo FA, Owolabi MO, Patton GC, Pourmalek F, Qorbani M, Rafay A, Rai RK, Ranabhat CL, Reinig N, Safiri S, Salomon JA, Sanabria JR, Santos IS, Sartorius B, Sawhney M, Schmidhuber J, Schutte AE, Schmidt MI, Sepanlou SG, Shamsizadeh M, Sheikhbahaei S, Shin M-J, Shiri R, Shiue I, Roba HS, Silva DAS, Silverberg JI, Singh JA, Stranges S, Swaminathan S, Tabarés-Seisdedos R, Tadese F, Tedla BA, Tegegne BS, Terkawi AS, Thakur JS, Tonelli M, ToporMadry R, Tyrovolas S, Ukwaja KN, Uthman OA, Vaezghasemi M, Vasankari T, Vlassov VV, Vollset SE, Weiderpass E, Werdecker A, Wesana J, Westerman R, Yano Y, Yonemoto N, Yonga G, Zaidi Z, Zenebe ZM, Zipkin B, Murray CJL. GBD 2015 Obesity Collaborators. Health Effects of Overweight and Obesity in 195 Countries over 25 Years. N. Engl. J. Med. 2017; 377:13-27. [PubMed: 28604169]

3. Di Dalmazi G, Vicennati V, Pasquali R, Pagotto U. The unrelenting fall of the pharmacological treatment of obesity. Endocrine. 2013; 44:598-609. [PubMed: 23677499]

4. Westmoreland P, Krantz MJ, Mehler PS. Medical Complications of Anorexia Nervosa and Bulimia. Am. J. Med. 2016; 129:30-7. [PubMed: 26169883]

5. Li J, Song J, Zaytseva YY, Liu Y, Rychahou P, Jiang K, Starr ME, Kim JT, Harris JW, Yiannikouris FB, Katz WS, Nilsson PM, Orho-Melander M, Chen J, Zhu H, Fahrenholz T, Higashi RM, Gao T, Morris AJ, Cassis LA, Fan TW-M, Weiss HL, Dobner PR, Melander O, Jia J, Evers BM. An obligatory role for neurotensin in high-fat-diet-induced obesity. Nature. 2016; 533:411-415. [PubMed: 27193687]

6. Carraway R, Leeman SE. The Isolation of a New Hypotensive Peptide, Neurotensin, from Bovine Hypothalami. J. Biol. Chem. 1973; 248:6854-6861. [PubMed: 4745447]

7. Carraway R, Leeman SE. Characterization of radioimmunoassayable neurotensin in the rat. Its differential distribution in the central nervous system, small intestine, and stomach. J. Biol. Chem. 1976; 251:7045-7052. [PubMed: 993203]

8. Kislauskis E, Bullock B, McNeil S, Dobner PR. The rat gene encoding neurotensin and neuromedin N. Structure, tissue-specific expression, and evolution of exon sequences. J. Biol. Chem. 1988; 263:4963-4968. [PubMed: 2832414]

9. Vincent J-P, Mazella J, Kitabgi P. Neurotensin and neurotensin receptors. Trends Pharmacol. Sci. 1999; 20:302-309. [PubMed: 10390649]

10. Rökaeus ÅKE, Fried G, Lundberg JANM. Occurrence, storage and release of neurotensin-like immunoreactivity from the adrenal gland. Acta Physiol. Scand. 1984; 120:373-380. [PubMed: 6741572]

11. Mustain WC, Rychahou PG, Evers BM. The role of neurotensin in physiologic and pathologic processes. 2011 
12. Clineschmidt BV, McGuffin JC, Bunting PB. Neurotensin: Antinocisponsive action in rodents. Eur. J. Pharmacol. 1979; 54:129-139. [PubMed: 421735]

13. Christ-Crain M, Stoeckli R, Ernst A, Morgenthaler NG, Bilz S, Korbonits M, Struck J, Bergmann A, Müller B, Keller U. Effect of Gastric Bypass and Gastric Banding on Proneurotensin Levels in Morbidly Obese Patients. J. Clin. Endocrinol. Metab. 2006; 91:3544-3547. [PubMed: 16787986]

14. Gevaert B, Wynendaele E, Stalmans S, Bracke N, D’Hondt M, Smolders I, van Eeckhaut A, De Spiegeleer B. Blood-brain barrier transport kinetics of the neuromedin peptides NMU, NMN, NMB and NT. Neuropharmacology. 2016; 107:460-470. [PubMed: 27040796]

15. Ratner C, Skov LJ, Raida Z, Bächler T, Bellmann-Sickert K, Le Foll C, Sivertsen B, Dalbøge LS, Hartmann B, Beck-Sickinger AG, Madsen AN, Jelsing J, Holst JJ, Lutz TA, Andrews ZB, Holst B. Effects of Peripheral Neurotensin on Appetite Regulation and Its Role in Gastric Bypass Surgery. Endocrinology. 2016; 157:3482-3492. [PubMed: 27580810]

16. Uhl GR, Goodman RR, Snyder SH. Neurotensin-containing cell bodies, fibers and nerve terminals in the brain stem of the rat: Immunohistochemical mapping. Brain Res. 1979; 167:77-91. [PubMed: 378326]

17. Kahn D, Abrams GM, Zimmerman EA, Carraway R, Leeman SE. Neurotensin neurons in the rat hypothalamus: an immunocytochemical study. Endocrinology. 1980; 107:47-54. [PubMed: 6991249]

18. Jennes L, Stumpf WE, Kalivas PW. Neurotensin: Topographical distribution in rat brain by immunohistochemistry. J. Comp. Neurol. 1982; 210:211-224. [PubMed: 6754769]

19. Kahn D, Hou-Yu A, Zimmerman EA. LOCALIZATION OF NEUROTENSIN IN THE HYPOTHALAMUS*. Ann. N. Y. Acad. Sci. 1982; 400:117-131. [PubMed: 6132575]

20. Ibata Y, Kawakami F, Fukui K, Okamura H, Obata-Tsuto HL, Tsuto T, Terubayashi H. Morphological survey of neurotensin-like immunoreactive neurons in the hypothalamus. Peptides. 1984; 5(Supplem):109-120. [PubMed: 6435100]

21. Triepel J, Mader J, Weindl A, Heinrich D, Forssmann WG, Metz J. Distribution of NT-IR perikarya in the brain of the guinea pig with special reference to cardiovascular centers in the medulla oblongata. Histochemistry. 1984; 81:509-516. [PubMed: 6526693]

22. Lein ES, Hawrylycz MJ, Ao N, Ayres M, Bensinger A, Bernard A, Boe AF, Boguski MS, Brockway KS, Byrnes EJ, Chen L, Chen L, Chen T-M, Chi Chin M, Chong J, Crook BE, Czaplinska A, Dang CN, Datta S, Dee NR, Desaki AL, Desta T, Diep E, Dolbeare TA, Donelan MJ, Dong H-W, Dougherty JG, Duncan BJ, Ebbert AJ, Eichele G, Estin LK, Faber C, Facer BA, Fields R, Fischer SR, Fliss TP, Frensley C, Gates SN, Glattfelder KJ, Halverson KR, Hart MR, Hohmann JG, Howell MP, Jeung DP, Johnson RA, Karr PT, Kawal R, Kidney JM, Knapik RH, Kuan CL, Lake JH, Laramee AR, Larsen KD, Lau C, Lemon TA, Liang AJ, Liu Y, Luong LT, Michaels J, Morgan JJ, Morgan RJ, Mortrud MT, Mosqueda NF, Ng LL, Ng R, Orta GJ, Overly CC, Pak TH, Parry SE, Pathak SD, Pearson OC, Puchalski RB, Riley ZL, Rockett HR, Rowland SA, Royall JJ, Ruiz MJ, Sarno NR, Schaffnit K, Shapovalova NV, Sivisay T, Slaughterbeck CR, Smith SC, Smith KA, Smith BI, Sodt AJ, Stewart NN, Stumpf K-R, Sunkin SM, Sutram M, Tam A, Teemer CD, Thaller C, Thompson CL, Varnam LR, Visel A, Whitlock RM, Wohnoutka PE, Wolkey CK, Wong VY, Wood M, Yaylaoglu MB, Young RC, Youngstrom BL, Feng Yuan X, Zhang B, Zwingman TA, Jones AR. Genome-wide atlas of gene expression in the adult mouse brain. Nature. 2007; 445:168-176. [PubMed: 17151600]

23. Seroogy KB, Mehta A, Fallon JH. Neurotensin and cholecystokinin coexistence within neurons of the ventral mesencephalon: projections to forebrain. Exp. Brain Res. 1987; 68:277-289. [PubMed: 3319664]

24. Zhou Q-Y, Palmiter RD. Dopamine-deficient mice are severely hypoactive, adipsic, and aphagic. Cell. 1995; 83:1197-1209. [PubMed: 8548806]

25. Tanaka K, Masu M, Nakanishi S. Structure and functional expression of the cloned rat neurotensin receptor. Neuron. 1990; 4:847-854. [PubMed: 1694443]

26. Chalon P, Vita N, Kaghad M, Guillemot M, Bonnin J, Delpech B, Le Fur G, Ferrara P, Caput D. Molecular cloning of a levocabastine-sensitive neurotensin binding site. FEBS Lett. 1996; 386:9194. [PubMed: 8647296] 
27. Nouel D, Sarret P, Vincent J-P, Mazella J, Beaudet A. Pharmacological, molecular and functional characterization of glial neurotensin receptors. Neuroscience. 1999; 94:1189-1197. [PubMed: 10625058]

28. Woodworth HL, Batchelor HM, Beekly BG, Bugescu R, Brown JA, Kurt G, Fuller PM, Leinninger GM. Neurotensin Receptor-1 Identifies a Subset of Ventral Tegmental Dopamine Neurons that Coordinates Energy Balance. Cell Rep. 2017; 20:1881-1892. [PubMed: 28834751]

29. Mazella J. Sortilin/neurotensin receptor-3: a new tool to investigate neurotensin signaling and cellular trafficking? Cell. Signal. 2001; 13:1-6. [PubMed: 11257441]

30. Elde R, Schalling M, Ceccatelli S, Nakanishi S, Hökfelt T. Localization of neuropeptide receptor mRNA in rat brain: Initial observations using probes for neurotensin and substance $\mathrm{P}$ receptors. Neurosci. Lett. 1990; 120:134-138. [PubMed: 1705671]

31. Alexander MJ, Leeman SE. Widespread expression in adult rat forebrain of mRNA encoding highaffinity neurotensin receptor. J. Comp. Neurol. 1998; 402:475-500. [PubMed: 9862322]

32. Walker N, Lepee-Lorgeoux I, Fournier J, Betancur C, Rostene W, Ferrara P, Caput D. Tissue distribution and cellular localization of the levocabastine-sensitive neurotensin receptor mRNA in adult rat brain. Mol. Brain Res. 1998; 57:193-200. [PubMed: 9675417]

33. Sarret P, Krzywkowski P, Segal L, Nielsen MS, Petersen CM, Mazella J, Stroh T, Beaudet A. Distribution of NTS3 receptor/sortilin mRNA and protein in the rat central nervous system. J. Comp. Neurol. 2003; 461:483-505. [PubMed: 12746864]

34. Sarret P, Perron A, Stroh T, Beaudet A. Immunohistochemical distribution of NTS2 neurotensin receptors in the rat central nervous system. J. Comp. Neurol. 2003; 461:520-538. [PubMed: 12746866]

35. Fassio A, Evans G, Grisshammer R, Bolam JP, Mimmack M, Emson PC. Distribution of the neurotensin receptor NTS1 in the rat CNS studied using an amino-terminal directed antibody. Neuropharmacology. 2000; 39:1430-1442. [PubMed: 10818259]

36. Palacios JM, Pazos A, Dietl MM, Schlumpf M, Lichtensteiger W. The ontogeny of brain neurotensin receptors studied by autoradiography. Neuroscience. 1988; 25:307-317. [PubMed: 2839800]

37. Opland D, Sutton A, Woodworth H, Brown J, Bugescu R, Garcia A, Christensen L, Rhodes C, Myers M, Leinninger G. Loss of neurotensin receptor-1 disrupts the control of the mesolimbic dopamine system by leptin and promotes hedonic feeding and obesity. Mol. Metab. 2013; 2:423434. [PubMed: 24327958]

38. Hershberger, P., Hedrick, M., Peddibhotla, S., Maloney, P., Li, Y., Milewski, M., Gosalia, P., Gray, W., Mehta, A., Sugarman, E., Hood, B., Suyama, E., Nguyen, K., Heynen-Genel, S., Vasile, S., Salaniwal, S., Stonich, D., Su, Y., Mangravita-Novo, A., Vicchiarelli, M., Smith, LH., Roth, G., Diwan, J., Chung, TDY., Caron, MG., Thomas, JB., Pinkerton, AB., Barak, LR. Small Molecule Agonists for the Neurotensin 1 Receptor (NTR1 Agonists). Bethesda (MD): 2010.

39. Boules M, Johnston H, Tozy J, Smith K, Li Z, Richelson E. Analgesic synergy of neurotensin receptor subtype 2 agonist NT79 and morphine. Behav. Pharmacol. 2011; 22:573-81. [PubMed: 21691202]

40. Pettibone DJ, Hess JF, Hey PJ, Jacobson MA, Leviten M, Lis EV, Mallorga PJ, Pascarella DM, Snyder MA, Williams JB, Zeng Z. The Effects of Deleting the Mouse Neurotensin Receptor NTR1 on Central and Peripheral Responses to Neurotensin. J. Pharmacol. Exp. Ther. 2002; 300:305 LP313. [PubMed: 11752130]

41. Remaury A, Vita N, Gendreau S, Jung M, Arnone M, Poncelet M, Culouscou J-M, Le Fur G, Soubrié P, Caput D, Shire D, Kopf M, Ferrara P. Targeted inactivation of the neurotensin type 1 receptor reveals its role in body temperature control and feeding behavior but not in analgesia. Brain Res. 2002; 953:63-72. [PubMed: 12384239]

42. Maeno H, Yamada K, Santo-Yamada Y, Aoki K, Sun Y-J, Sato E, Fukushima T, Ogura H, Araki T, Kamichi S, Kimura I, Yamano M, Maeno-Hikichi Y, Watase K, Aoki S, Kiyama H, Wada E, Wada K. Comparison of mice deficient in the high- or low-affinity neurotensin receptors, Ntsr1 or Ntsr2, reveals a novel function for Ntsr2 in thermal nociception. Brain Res. 2004; 998:122-129.

[PubMed: 14725975] 
43. Kim ER, Leckstrom A, Mizuno TM. Impaired anorectic effect of leptin in neurotensin receptor 1deficient mice. Behav. Brain Res. 2008; 194:66-71. [PubMed: 18639588]

44. Liang Y, Boules M, Li Z, Williams K, Miura T, Oliveros A, Richelson E. Hyperactivity of the dopaminergic system in NTS1 and NTS2 null mice. Neuropharmacology. 2010; 58:1199-1205. [PubMed: 20211191]

45. Mechanic JA, Sutton JE, Berson AE, Wu X, Kwan J, Schreiber R, Pang Z, Button DC. Involvement of the neurotensin receptor 1 in the behavioral effects of two neurotensin agonists, NT-2 and NT69L: Lack of hypothermic, antinociceptive and antipsychotic actions in receptor knockout mice. Eur. Neuropsychopharmacol. 2009; 19:466-475. [PubMed: 19223157]

46. Rioux F, Quirion R, St-Pierre S, Regoli D, Jolicoeur FB, Bélanger F, Barbeau A. The hypotensive effect of centrally administered neutrotensin in rats. Eur. J. Pharmacol. 1981; 69:241-247. [PubMed: 7215426]

47. Nemeroff CB, Bissette G, Prange AJ Jr, Loosen PT, Steven Barlow T, Lipton MA. Neurotensin: Central nervous system effects of a hypothalamic peptide. Brain Res. 1977; 128:485-496. [PubMed: 406965]

48. Cooke JH, Patterson M, Patel SR, Smith KL, Ghatei MA, Bloom SR, Murphy KG. Peripheral and Central Administration of Xenin and Neurotensin Suppress Food Intake in Rodents. Obesity. 2009; 17:1135-1143. [PubMed: 19214175]

49. Hawkins MF, Baker JD, Baumeister AA. Neurotensin-induced polydipsia: a structure-activity study. Brain Res. 1989; 487:188-191. [PubMed: 2752285]

50. Levine AS, Kneip J, Grace M, Morley JE. Effect of centrally administered neurotensin on multiple feeding paradigms. Pharmacol. Biochem. Behav. 1983; 18:19-23.

51. Blaha CD, Coury A, Fibiger HC, Phillips AG. Effects of neurotensin on dopamine release and metabolism in the rat striatum and nucleus accumbens: Cross-validation using in vivo voltammetry and microdialysis. Neuroscience. 1990; 34:699-705. [PubMed: 2352647]

52. Ciriello J, Zhang T-X. Cardiovascular effects of neurotensin microinjections into the nucleus of the solitary tract. Brain Res. 1997; 749:35-43. [PubMed: 9070625]

53. de Beaurepaire R, Suaudeau C. Anorectic effect of calcitonin, neurotensin and bombesin infused in the area of the rostral part of the nucleus of the tractus solitarius in the rat. Peptides. 1988; 9:729733. [PubMed: 3226951]

54. Kalivas PW, Nemeroff CB, Miller JS, Prange AJ. Microinjection of neurotensin into the ventral tegmental area produces hypothermia: Evaluation of dopaminergic mediation. Brain Res. 1985; 326:219-227. [PubMed: 2982460]

55. Voyer D, Lévesque D, Rompré P-P. Repeated ventral midbrain neurotensin injections sensitize to amphetamine-induced locomotion and ERK activation: A role for NMDA receptors. Neuropharmacology. 2017; 112(Part):150-163. [PubMed: 27267684]

56. Kalivas PW, Duffy P. Effect of acute and daily neurotensin and enkephalin treatments on extracellular dopamine in the nucleus accumbens. J. Neurosci. 1990; 10:2940 LP-2949. [PubMed: 1697899]

57. Cador M, Kelley AE, Le Moal M, Stinus L. Ventral tegmental area infusion of substance P, neurotensin and enkephalin: Differential effects on feeding behavior. Neuroscience. 1986; 18:659669. [PubMed: 2427971]

58. Hawkins MF. Aphagia in the rat following microinjection of neurotensin into the ventral tegmental area. Life Sci. 1986; 38:2383-2388. [PubMed: 3459947]

59. Hawkins MF. Central nervous system neurotensin and feeding. Physiol. Behav. 1986; 36:1-8. [PubMed: 3952166]

60. Stanley BG, Hoebel BG, Leibowitz SF. Neurotensin: Effects of hypothalamic and intravenous injections on eating and drinking in rats. Peptides. 1983; 4:493-500. [PubMed: 6685868]

61. Benmoussa M, Chait A, Loric G, De Beaurepaire R. Low doses of neurotensin in the preoptic area produce hyperthermia. Comparison with other brain sites and with neurotensin-induced analgesia. Brain Res. Bull. 1996; 39:275-279. [PubMed: 8705314]

62. Kalivas PW, Nemeroff CB, Prange AJ Jr. Neurotensin microinjection into the nucleus accumbens antagonizes dopamine-induced increase in locomotion and rearing. Neuroscience. 1984; 11:919930. [PubMed: 6738859] 
63. Tanganelli S, O'connor WT, Ferraro L, Bianchi C, Beani L, Ungerstedt U, Fuxe K. Facilitation of gaba release by neurotensin is associated with a reduction of dopamine release in rat nucleus accumbens. Neuroscience. 1994; 60:649-657. [PubMed: 7936192]

64. Smith KE, Boules M, Williams K, Richelson E. NTS1 and NTS2 mediate analgesia following neurotensin analog treatment in a mouse model for visceral pain. Behav. Brain Res. 2012; 232:9397. [PubMed: 22504145]

65. Fantegrossi WE, Ko MCH, Woods JH, Richelson E. Antinociceptive, hypothermic, hypotensive, and reinforcing effects of a novel neurotensin receptor agonist, NT69L, in rhesus monkeys. Pharmacol. Biochem. Behav. 2005; 80:341-349. [PubMed: 15680187]

66. Tanganelli S, Antonelli T, Tomasini MC, Beggiato S, Fuxe K, Ferraro L. Relevance of Dopamine D2/Neurotensin NTS1 and NMDA/Neurotensin NTS1 Receptor Interaction in Psychiatric and Neurodegenerative Disorders. Curr. Med. Chem. 2012; 19:304-316. [PubMed: 22335510]

67. Feifel D, Goldenberg J, Melendez G, Shilling PD. The acute and subchronic effects of a brainpenetrating, neurotensin-1 receptor agonist on feeding, body weight and temperature. Neuropharmacology. 2010; 58:195-198. [PubMed: 19596358]

68. Cáceda R, Kinkead B, Owens MJ, Nemeroff CB. Virally Mediated Increased Neurotensin 1 Receptor in the Nucleus Accumbens Decreases Behavioral Effects of Mesolimbic System Activation. J. Neurosci. 2005; 25:11748 LP-11756. [PubMed: 16354933]

69. Vadnie CA, Hinton DJ, Choi S, Choi Y, Ruby CL, Oliveros A, Prieto ML, Park JH, Choi D-S. Activation of neurotensin receptor type 1 attenuates locomotor activity. Neuropharmacology. 2014; 85:482-492. [PubMed: 24929110]

70. Ferraro L, Tiozzo Fasiolo L, Beggiato S, Borelli AC, Pomierny-Chamiolo L, Frankowska M, Antonelli T, Tomasini MC, Fuxe K, Filip M. Neurotensin: A role in substance use disorder? J. Psychopharmacol. 2016; 30:112-127. [PubMed: 26755548]

71. Binder EB, Kinkead B, Owens MJ, Nemeroff CB. The role of neurotensin in the pathophysiology of schizophrenia and the mechanism of action of antipsychotic drugs. Biol. Psychiatry. 2001; 50:856-872. [PubMed: 11743941]

72. Antonelli T, Tomasini MC, Fuxe K, Agnati LF, Tanganelli S, Ferraro L. Receptor-receptor interactions as studied with microdialysis. Focus on NTR/D2 interactions in the basal ganglia. J. Neural Transm. 2007; 114:105-113. [PubMed: 16983483]

73. Boules MM, Fredrickson P, Muehlmann AM, Richelson E. Elucidating the Role of Neurotensin in the Pathophysiology and Management of Major Mental Disorders. Behav. Sci. (Basel). 2014; 4:125-153. [PubMed: 25379273]

74. O'Connor WT. Functional neuroanatomy of the ventral striopallidal GABA pathway: New sites of intervention in the treatment of schizophrenia. J. Neurosci. Methods. 2001; 109:31-39. [PubMed: 11489297]

75. Patterson CM, Wong JMT, Leinninger GM, Allison MB, Mabrouk OS, Kasper CL, Gonzalez IE, Mackenzie A, Jones JC, Kennedy RT, Myers MG. Ventral tegmental area neurotensin signaling links the lateral hypothalamus to locomotor activity and striatal dopamine efflux in male mice. Endocrinology. 2015; 156:1692-1700. [PubMed: 25734363]

76. Fitzpatrick K, Winrow CJ, Gotter AL, Millstein J, Arbuzova J, Brunner J, Kasarskis A, Vitaterna MH, Renger JJ, Turek FW. Altered Sleep and Affect in the Neurotensin Receptor 1 Knockout Mouse. Sleep. 2012; 35:949-956. [PubMed: 22754041]

77. Robledo P, Maldonado R, Koob GF. Neurotensin injected into the nucleus accumbens blocks the psychostimulant effects of cocaine but does not attenuate cocaine self-administration in the rat. Brain Res. 1993; 622:105-112. [PubMed: 8242350]

78. Boules M, Warrington L, Fauq A, McCormick D, Richelson E. A novel neurotensin analog blocks cocaine- and d-amphetamine-induced hyperactivity. Eur. J. Pharmacol. 2001; 426:73-76. [PubMed: 11525773]

79. Fredrickson P, Boules M, Yerbury S, Richelson E. Blockade of nicotine-induced locomotor sensitization by a novel neurotensin analog in rats. Eur. J. Pharmacol. 2003; 458:111-118. [PubMed: 12498914] 
80. Boules M, Oliveros A, Liang Y, Williams K, Shaw A, Robinson J, Fredrickson P, Richelson E. A neurotensin analog, NT69L, attenuates intravenous nicotine self-administration in rats. Neuropeptides. 2011; 45:9-16. [PubMed: 21047685]

81. Liang Y, Boules M, Shaw AM, Williams K, Fredrickson P, Richelson E. Effect of a novel neurotensin analog, NT69L, on nicotine-induced alterations in monoamine levels in rat brain. Brain Res. 2008; 1231:6-15. [PubMed: 18687313]

82. Panayi F, Colussi-Mas J, Lambás-Señas L, Renaud B, Scarna H, Bérod A. Endogenous Neurotensin in the Ventral Tegmental Area Contributes to Amphetamine Behavioral Sensitization. Neuropsychopharmacology. 2004; 30:1300638.

83. Felszeghy K, Espinosa JM, Scarna H, Bérod A, Rostène W, Pélaprat D. Neurotensin receptor antagonist administered during cocaine withdrawal decreases locomotor sensitization and conditioned place preference. Neuropsychopharmacology. 2007; 32:2601-2610. [PubMed: 17356568]

84. Nemeroff CB. The interaction of neurotensin with dopaminergic pathways in the central nervous system: Basic neurobiology and implications for the pathogenesis and treatment of schizophrenia. Psychoneuroendocrinology. 1986; 11:15-37. [PubMed: 2871577]

85. Watts AG, Boyle CN. The functional architecture of dehydration-anorexia. Physiol. Behav. 2010; 100:472-477. [PubMed: 20399797]

86. Kelly AB, Watts AG. Mediation of Dehydration-Induced Peptidergic Gene Expression in the Rat Lateral Hypothalamic Area by Forebrain Afferent Projections. 1996; 246

87. Woodworth HL, Beekly BG, Batchelor HM, Bugescu R, Perez-Bonilla P, Schroeder LE, Leinninger GM. Lateral Hypothalamic Neurotensin Neurons Orchestrate Dual Weight Loss Behaviors via Distinct Mechanisms. Cell Rep. 2017 In Press.

88. Chakfe Y, Bourque CW. Excitatory peptides and osmotic pressure modulate mechanosensitive cation channels in concert. Nat Neurosci. 2000; 3:572-579. [PubMed: 10816313]

89. Sahu A. Effects of chronic central leptin infusion on proopiomelanocortin and neurotensin gene expression in the rat hypothalamus. Neurosci. Lett. 2008; 440:125-129. [PubMed: 18562101]

90. Sahu A. Evidence Suggesting That Galanin (GAL), Melanin-Concentrating Hormone (MCH), Neurotensin (NT), Proopiomelanocortin (POMC) and Neuropeptide Y (NPY) Are Targets of Leptin Signaling in the Hypothalamus. Endocrinology. 1998; 139:795-798. [PubMed: 9449656]

91. Nicot A, Rowe WB, De Kloet ER, Betancur C, Jessop DS, Lightman SL, Quirion R, Rostène W, Bérod A. Endogenous Neurotensin Regulates Hypothalamic-Pituitary-Adrenal Axis Activity and Peptidergic Neurons in the Rat Hypothalamic Paraventricular Nucleus. J. Neuroendocrinol. 1997; 9:263-269. [PubMed: 9147289]

92. Elias CF, Kelly JF, Lee CE, Ahima RS, Drucker DJ, Saper CB, Elmquist JK. Chemical Characterization of Leptin-Activated Neurons in the Rat. Brain. 2000; 281:261-281.

93. Uehara Y, Shimizu H, Ohtani K, Sato N, Mori M. Hypothalamic corticotropin-releasing hormone is a mediator of the anorexigenic effect of leptin. Diabetes. 1998; 47:890 LP-893. [PubMed: 9604864]

94. Beck B, Nicolas J-P, Burlet C. Neurotensin decreases with fasting in the ventromedian nucleus of obese Zucker rats. Metabolism. 1995; 44:972-975. [PubMed: 7637654]

95. Lam DD, Zhou L, Vegge A, Xiu PY, Christensen BT, Osundiji MA, Yueh C, Evans ML, Heisler LK. Distribution and neurochemical characterization of neurons within the nucleus of the solitary tract responsive to serotonin agonist-induced hypophagia. Behav. Brain Res. 2009; 196:139-143. [PubMed: 18762217]

96. Rinaman L, Verbalis JG, Stricker EM, Hoffman GE. Distribution and neurochemical phenotypes of caudal medullary neurons activated to express cFos following peripheral administration of cholecystokinin. J. Comp. Neurol. 1993; 338:475-490. [PubMed: 8132858]

97. Ohinata K, Shimano T, Yamauchi R, Sakurada S, Yanai K, Yoshikawa M. The anorectic effect of neurotensin is mediated via a histamine H1 receptor in mice. Peptides. 2004; 25:2135-2138. [PubMed: 15572202]

98. Seutin V, Massotte L, Dresse A. Electrophysiological effects of neurotensin on dopaminergic neurones of the ventral tegmental area of the rat in vitro. Neuropharmacology. 1989; 28:949-954. [PubMed: 2572997] 
99. Stuhrman K, Roseberry AG. Neurotensin inhibits both dopamine- and GABA-mediated inhibition of ventral tegmental area dopamine neurons. J. Neurophysiol. 2015; 114:1734 LP-1745. [PubMed: 26180119]

100. Leinninger GM, Opland DM, Jo Y-H, Faouzi M, Christensen L, Cappellucci LA, Rhodes CJ, Gnegy ME, Becker JB, Pothos EN, Seasholtz AF, Thompson RC, Myers MG. Leptin action via neurotensin neurons controls orexin, the mesolimbic dopamine system and energy balance. Cell Metab. 2011; 14:313-323. [PubMed: 21907138]

101. Brown JA, Bugescu R, Mayer TA, Gata-Garcia A, Kurt G, Woodworth HL, Leinninger GM. Loss of Action via Neurotensin-Leptin Receptor Neurons Disrupts Leptin and Ghrelin-Mediated Control of Energy Balance. Endocrinology. 2017; 158:1271-1288. [PubMed: 28323938]

102. Goforth PB, Leinninger GM, Patterson CM, Satin LS, Myers MG. Leptin Acts via Lateral Hypothalamic Area Neurotensin Neurons to Inhibit Orexin Neurons by Multiple GABAIndependent Mechanisms. J. Neurosci. 2014; 34:11405 LP-11415. [PubMed: 25143620]

103. Grossberg AJ, Zhu X, Leinninger GM, Levasseur PR, Braun TP, Myers MG, Marks DL. Inflammation-Induced Lethargy Is Mediated by Suppression of Orexin Neuron Activity. J. Neurosci. 2011; 31:11376 LP-11386. [PubMed: 21813697]

104. Allison DB, Casey DE. Antipsychotic-induced weight gain: A review of the literature. J. Clin. Psychiatry. 2001; 62:22-31.

105. Kim SF, Huang AS, Snowman AM, Teuscher C, Snyder SH. Antipsychotic drug-induced weight gain mediated by histamine $\mathrm{H} 1$ receptor-linked activation of hypothalamic AMP-kinase. Proc. Natl. Acad. Sci. 2007; 104:3456-3459. [PubMed: 17360666]

106. Rojczyk E, Pałasz A, Wiaderkiewicz R. Effect of short and long-term treatment with antipsychotics on orexigenic/anorexigenic neuropeptides expression in the rat hypothalamus. Neuropeptides. 2015; 51:31-42. [PubMed: 25888224]

107. Berridge KC, Ho C-Y, Richard JM, DiFeliceantonio AG. The tempted brain eats: Pleasure and desire circuits in obesity and eating disorders. Brain Res. 2010; 1350:43-64. [PubMed: 20388498]

108. Folley BS, Park S. Relative food preference and hedonic judgments in schizophrenia. Psychiatry Res. 2010; 175:33-37. [PubMed: 19931919]

109. Hübner H, Schellhorn T, Gienger M, Schaab C, Kaindl J, Leeb L, Clark T, Möller D, Gmeiner P. Structure-guided development of heterodimer-selective GPCR ligands. 2016; 7:12298.

110. Cáceda R, Kinkead B, Nemeroff CB. Neurotensin: Role in psychiatric and neurological diseases. Peptides. 2006; 27:2385-2404. [PubMed: 16891042]

111. St-Gelais F, Jomphe C, Trudeau LÉ. The role of neurotensin in central nervous system pathophysiology: What is the evidence? J. Psychiatry Neurosci. 2006; 31:229-245. [PubMed: 16862241]

112. Kistner A, Lhommée E, Krack P. Mechanisms of Body Weight Fluctuations in Parkinson's Disease. Front. Neurol. 2014; 5:84. [PubMed: 24917848]

113. Mesnage V, Houeto JL, Bonnet AM, Clavier I, Arnulf I, Agid Y. Neurokinin B, Neurotensin, and Cannabinoid Receptor. 2004; 27:108-110.

114. Alexander MJ, Kiraly ZJ, Leeman SE. Sexually dimorphic distribution of neurotensin/ neuromedin N mRNA in the rat preoptic area. J. Comp. Neurol. 1991; 311:84-96. [PubMed: 1939736]

115. Alexanders MJ, Dobner PR, Miller MA, Bullock BP, Dorsa DM, Leeman SE. Estrogen Induces Neurotensin/Neuromedin N Messenger Ribonucleic Acid in a Preoptic Nucleus Essential for the Preovulatory Surge of Luteinizing Hormone in the Rat*. Endocrinology. 1989; 125:2111-2117. [PubMed: 2791980]

116. Dungan Lemko HM, Naderi R, Adjan V, Jennes LH, Navarro VM, Clifton DK, Steiner RA. Interactions between neurotensin and GnRH neurons in the positive feedback control of GnRH/LH secretion in the mouse. Am. J. Physiol. - Endocrinol. Metab. 2009; 298:E80 LP-E88. [PubMed: 19861584]

117. Santollo J, Torregrossa A-M, Eckel LA. Estradiol acts in the medial preoptic area, arcuate nucleus, and dorsal raphe nucleus to reduce food intake in ovariectomized rats. Horm. Behav. 2011; 60:86-93. [PubMed: 21439964] 
118. Klump KL, Keel PK, Sisk C, Burt SA. Preliminary evidence that estradiol moderates genetic influences on disordered eating attitudes and behaviors during puberty. Psychol. Med. 2010; 40:1745-1753. [PubMed: 20059800]

119. Cai H, Haubensak W, Anthony TE, Anderson DJ. Central amygdala PKC-[delta]+ neurons mediate the influence of multiple anorexigenic signals. Nat Neurosci. 2014; 17:1240-1248. [PubMed: 25064852]

120. Yamano M, Hillyard CJ, Girgis S, Emson PC, MacIntyre I, Tohyama M. Projection of neurotensin-like immunoreactive neurons from the lateral parabrachial area to the central amygdaloid nucleus of the rat with reference to the coexistence with calcitonin gene-related peptide. Exp. Brain Res. 1988; 71:603-610. [PubMed: 3262069]

121. Friederich H-C, Walther S, Bendszus M, Biller A, Thomann P, Zeigermann S, Katus T, Brunner R, Zastrow A, Herzog W. Grey matter abnormalities within cortico-limbic-striatal circuits in acute and weight-restored anorexia nervosa patients. Neuroimage. 2012; 59:1106-1113. [PubMed: 21967727]

122. Eckel LA, Houpt TA, Geary N. Estradiol treatment increases CCK-induced c-Fos expression in the brains of ovariectomized rats. Am. J. Physiol. - Regul. Integr. Comp. Physiol. 2002; 283:R1378 LP-R1385. [PubMed: 12429561]

123. Butera PC, Bradway DM, Cataldo NJ. Modulation of the satiety effect of cholecystokinin by estradiol. Physiol. Behav. 1993; 53:1235-1238. [PubMed: 8346313]

124. Yoshizawa M, Tashiro M, Fukudo S, Yanai K, Utsumi A, Kano M, Karahasi M, Endo Y, Morisita J, Sato Y, Adachi M, Itoh M, Hongo M. Increased Brain Histamine H1 Receptor Binding in Patients with Anorexia Nervosa. Biol. Psychiatry. 2009; 65:329-335. [PubMed: 18814859]

125. Maes M, Monteleone P, Bencivenga R, Goossens F, Maj M, van West D, Bosmans E, Scharpe S. Lower serum activity of prolyl endopeptidase in anorexia and bulimia nervosa. Psychoneuroendocrinology. 2001; 26:17-26. [PubMed: 11070331]

126. Kontis D, Theochari E. Dopamine in anorexia nervosa : a systematic review. 2008:496-515.

127. Cowdrey FA, Park RJ, Harmer CJ, McCabe C. Increased Neural Processing of Rewarding and Aversive Food Stimuli in Recovered Anorexia Nervosa. Biol. Psychiatry. 2011; 70:736-743. [PubMed: 21714958]

128. Scheurink AJW, Boersma GJ, Nergårdh R, Södersten P. Neurobiology of hyperactivity and reward: Agreeable restlessness in Anorexia Nervosa. Physiol. Behav. 2010; 100:490-495. [PubMed: 20361989]

129. Verhagen LAW, Luijendijk MCM, Hillebrand JJG, Adan RAH. Dopamine antagonism inhibits anorectic behavior in an animal model for anorexia nervosa. Eur. Neuropsychopharmacol. 2009; 19:153-160. [PubMed: 18977121]

130. Chartoff EH, Szczypka MS, Palmiter RD, Dorsa DM. Endogenous neurotensin attenuates dopamine-dependent locomotion and stereotypy. Brain Res. 2004; 1022:71-80. [PubMed: 15353215]

131. Lutter M, Bahl E, Hannah C, Hofammann D, Acevedo S, Cui H, McAdams CJ, Michaelson JJ. Novel and ultra-rare damaging variants in neuropeptide signaling are associated with disordered eating behaviors. PLoS One. 2017; 12:e0181556. [PubMed: 28846695]

132. Beck B, Stricker-Krongrad A, Burlet A, Nicolas JP, Burlet C. Changes in hypothalamic neurotensin concentrations and food intake in rats fed a high fat diet. Int. J. Obes. Relat. Metab. Disord. 1992; 16:361-6. [PubMed: 1319971]

133. Beck B, Burlet A, Nicolas JP, Burlet C. Hyperphagia in obesity is associated with a central peptidergic dysregulation in rats. J. Nutr. 1990; 120:806-11. [PubMed: 2366113]

134. Williams G, Cardoso H, Lee YC, Ghatei MA, Flatt PR, Bailey CJ, Bloom SR. Reduced hypothalamic neurotensin concentrations in the genetically obese diabetic (obob) mouse: Possible relationship to obesity. Metabolism. 1991; 40:1112-1116. [PubMed: 1943736]

135. Wilding JP, Gilbey SG, Bailey CJ, Batt RA, Williams G, Ghatei MA, Bloom SR. Increased neuropeptide-Y messenger ribonucleic acid (mRNA) and decreased neurotensin mRNA in the hypothalamus of the obese (ob/ob) mouse. Endocrinology. 1993; 132:1939-1944. [PubMed: 7682936] 
136. Boules M, Cusack B, Zhao L, Fauq A, McCormick DJ, Richelson E. A novel neurotensin peptide analog given extracranially decreases food intake and weight in rodents. Brain Res. 2000; 865:35-44. [PubMed: 10814731]

137. Stice E, Spoor S, Ng J, Zald DH. Relation of obesity to consummatory and anticipatory food reward. Physiol. Behav. 2009; 97:551-560. [PubMed: 19328819]

138. Shaw C, Buchanan KD. Intact neurotensin (NT) in human plasma: response to oral feeding. Regul. Pept. 1983; 7:145-153. [PubMed: 6197723]

139. Butler MG, Nelson TA, Driscoll DJ, Manzardo AM. High plasma neurotensin levels in children with Prader-Willi syndrome. Am. J. Med. Genet. Part A. 2015; 167:1773-1778.

140. Rovere C, Viale A, Nahon J, Kitabgi P. Impaired processing of brain proneurotensin and promelanin-concentrating hormone in obese fat/fat mice. Endocrinology. 1996; 137:2954-2958. [PubMed: 8770919] 


\section{HIGHLIGHTS}

- Nts modifies physiology in a site and receptor-specific manner

- Central Nts modulates feeding and locomotor activity that impact body weight

- $\quad$ Nts signaling via the Ventral Tegmental Area supports dual weight loss behaviors

- $\quad$ Alterations in Nts signaling may underlie disrupted body weight in disease 


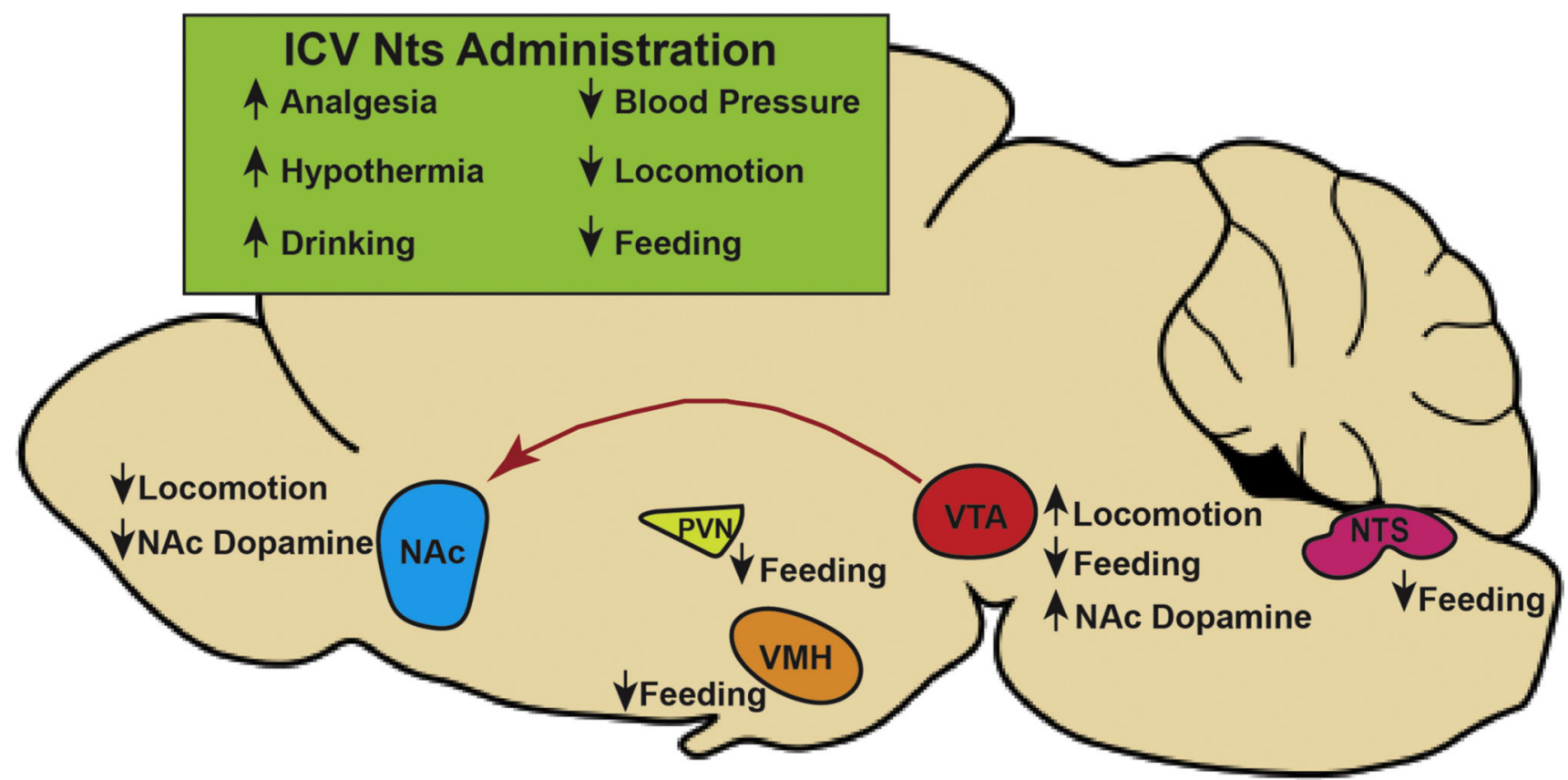

Figure 1. Differential physiological effects of ICV vs. site-specific Nts administration Central administration of Nts produces a wide range of physiological responses, including increases in analgesia, drinking, and hypothermia and decreases in blood pressure, locomotor activity, and feeding. Some of these effects are elicited when Nts is injected directly into specific brain regions. For example, reductions in feeding are observed when Nts is directly injected into the NTS, VMH, PVN, and VTA of rats. While decreases in locomotor activity are apparent upon administration of Nts into the NAc, centrally increased locomotor activity is observed with administration of Nts into the VTA, and this is likely due to the activation of the mesolimbic VTA DA neurons and the subsequent release of DA into the NAc that modulates motivated behaviors. In contrast, infusion of Nts directly into the NAc decreases DA release, and this is thought to be due to Nts-induced GABA release and D2R antagonism. 


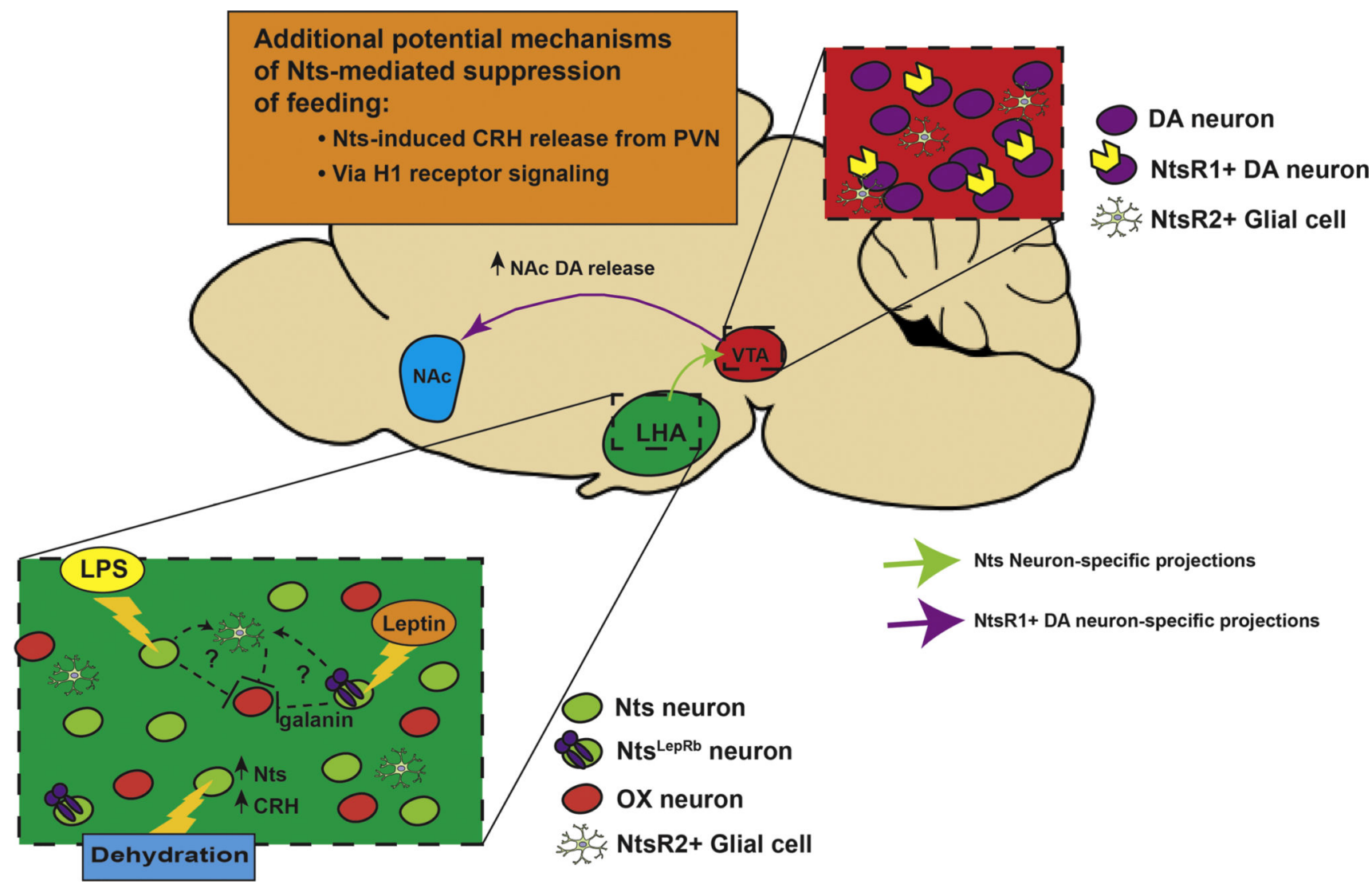

Figure 2. Mechanisms of Nts-mediated suppression of feeding

Nts induces reductions in feeding via multiple mechanisms. Within the VTA, a portion of

DA neurons express NtsR and respond to Nts with release of DA into the ventral striatum (e.g. NAc). The LHA, which contains a substantial number of Nts neurons, provides a source of Nts to the VTA. This LHA Nts $\rightarrow$ VTA circuit likely contributes to the anorectic response elicited by promoting NAc DA release. LHA Nts neurons additionally contribute to reductions in feeding via other mechanisms. LHA Nts neurons have been shown to hyperpolarize OX neurons in response to direct stimulation as well as in response to either leptin or LPS treatment. Though Nts ${ }^{\text {LepRb }}$ neurons respond to leptin to hyperpolarize OX neurons, they likely do so through a Nts-independent mechanism as OX neurons don't express NtsR isoforms. Nts ${ }^{\text {LepRb }}$ neurons additionally express the neuropeptide Galanin, which has also been demonstrated to hyperpolarize OX neurons. Since glia robustly express $\mathrm{NtsR} 2$, it is possible that $\mathrm{Nts}^{\mathrm{LepRb}}$ neurons act through astrocytes in the LHA to inhibit OX neurons. LPS induces activation of LHA Nts neurons, and subsequent reductions in feeding are likely mediated through similar mechanisms as described for leptin since OX neuronal activity is decreased with LPS administration. Finally, CRH gene expression in LHA Nts neurons correlates with the degree of anorexia that accompanies dehydration and these $\mathrm{CRH}$-expressing Nts neurons are thought to coordinate feeding with hydration status. Outside of the population of LHA Nts neurons, release of anorectic CRH from the PVN has been demonstrated to rely upon Nts action, and ICV Nts-induced decreases in feeding are mediated in part via $\mathrm{H}_{1}$ receptor signaling. 
Table 1

Distribution of Nts Cells in the Central Nervous System

Summary of structures reported to contain Nts immunoreactivity in brains from colchicine-treated rats [16-20] and guinea pigs [21]. Results convey the relative density of Nts-labeled cell bodies or fibers.

\begin{tabular}{|c|l|}
\hline \multicolumn{2}{|l|}{ KEY } \\
\hline NR & Not Reported \\
\hline+ & Few \\
\hline++ & Some \\
\hline+++ & Many \\
\hline++++ & Very Dense \\
\hline
\end{tabular}

\begin{tabular}{|c|c|c|c|}
\hline $\begin{array}{l}\text { Structures } \\
\text { Reported to } \\
\text { Contain Nts }\end{array}$ & $\begin{array}{l}\text { Supporting } \\
\text { Literature }\end{array}$ & $\begin{array}{l}\text { Density of } \\
\text { Cell Bodies }\end{array}$ & $\begin{array}{c}\text { Density } \\
\text { of } \\
\text { Fibers }\end{array}$ \\
\hline \multicolumn{4}{|l|}{ SPINAL CORD } \\
\hline Spinal cord: laminae I and II & 18 & NR & +++ \\
\hline Spinal cord: lamina III and IV & 18 & NR & ++ \\
\hline Spinal cord: lamina $X$ & 18 & + & ++ \\
\hline \multicolumn{4}{|l|}{ HINDBRAIN } \\
\hline Spinal trigeminal nucleus (Sp5C) & $16,18,21$ & $+++/++++$ & +++ \\
\hline Cuneate nucleus $(\mathrm{Cu})$ & 18 & NR & ++ \\
\hline Nucleus ambiguus (Amb) & 18 & ++ & +++ \\
\hline Pontine reticular nucleus (PnR) & 18 & NR & ++++ \\
\hline Pontine central gray (PCG) & 18 & NR & ++++ \\
\hline Mesencephalic Trigeminal Tract (me5) & 18 & NR & ++++ \\
\hline Trapezoid Nucleus (Tz) & 18,21 & +++ & +++ \\
\hline Gigantocellular reticular nucleus (Gi) & 18 & NR & ++++ \\
\hline Paragigantocellular reticular nucleus (PGi) & 21 & +++ & NR \\
\hline Parvocellular reticular nucleus & 18 & NR & ++ \\
\hline Lateral reticular nucleus (LRt) & 21 & ++ & NR \\
\hline Ventrolateral reticular formation & 18 & + & + \\
\hline Ventral reticular formation & 18 & NR & ++++ \\
\hline Nucleus linearis & 18 & NR & ++ \\
\hline Nucleus of the solitary tract (NST) & $16,18,21$ & $++/+++$ & $+++/++++$ \\
\hline Nucleus raphe magnus (RMg) & 18,21 & ++ & ++++ \\
\hline Nucleus raphe pallidus (RPA) & 21 & ++ & NR \\
\hline Nucleus raphe obscurus (RO) & 21 & ++ & NR \\
\hline Dorsal Cochlear nucleus (DC) & 16 & + & + \\
\hline Area Postrema (AP) & 18 & + & ++ \\
\hline Floor of the 4th Ventricle $(4 \mathrm{~V})$ & 16,18 & ++ & ++ \\
\hline Parabrachial nuclei (PB) & $16,18,21$ & $++/+++$ & $++/++++$ \\
\hline
\end{tabular}




\begin{tabular}{|c|c|c|c|}
\hline $\begin{array}{l}\text { Structures } \\
\text { Reported to } \\
\text { Contain Nts }\end{array}$ & $\begin{array}{l}\text { Supporting } \\
\text { Literature }\end{array}$ & $\begin{array}{l}\text { Density of } \\
\text { Cell Bodies }\end{array}$ & $\begin{array}{c}\text { Density } \\
\text { of } \\
\text { Fibers }\end{array}$ \\
\hline Locus coeruleus ( $\mathrm{LC})$ & $16,18,21$ & ++ & ++ \\
\hline \multicolumn{4}{|l|}{ MIDBRAIN } \\
\hline Dorsal raphe nucleus (DR) & $16,18,21$ & $++/+++$ & ++ \\
\hline Pontine raphe nucleus (PnR) & 18 & ++ & ++++ \\
\hline Median raphe nucleus (MnR); also known as "nucleus centralis superior" & 18 & ++ & ++ \\
\hline Periaqueductal gray (PAG); also known as "central gray" & $16,18,21$ & ++ & $++/+++$ \\
\hline Pretectal nucleus (APT) & 18 & NR & $+1++$ \\
\hline Medial pretectal area (MPT) & 18 & NR & ++ \\
\hline Lateral lemniscus (LL) & 18 & NR & +++ \\
\hline Ventral tegmental area (VTA); also known as "Paranigral nucleus" & $16,18,21$ & $+++/++++$ & ++ \\
\hline Interpeduncular fossa (IPF) & 18 & NR & ++ \\
\hline Substantia nigra pars compacta (SNC) & 18 & NR & +++ \\
\hline \multicolumn{4}{|l|}{ THALAMUS \& NEARBY REGIONS } \\
\hline Periventricular nuclei of Thalamus & 18 & ++ & ++ \\
\hline Medial Thalamic nuclei & 18 & $\mathrm{NR}$ & ++ \\
\hline Rhomboid thalamic nucleus $(\mathbf{R h})$ & 18 & NR & +++ \\
\hline Reuniens thalamic nucleus (Re) & 18 & $\mathrm{NR}$ & + \\
\hline Posteromedian Thalamic nucleus & 18 & NR & + \\
\hline Parafascicular Thalamic nucleus (PF) & 21 & +++ & NR \\
\hline Medial geniculate (MG) & 18 & NR & $+/++$ \\
\hline Lateral Habenula (LHb) & 18 & + & NR \\
\hline \multicolumn{4}{|l|}{ HYPOTHALAMUS \& NEARBY REGIONS } \\
\hline Posterior hypothalamic nucleus & 17,19 & + & + \\
\hline Dorsal hypothalamus & 18 & NR & ++++ \\
\hline Dorsomedial hypothalamic nucleus (DMH) & $17-19,21$ & $+/+++$ & ++ \\
\hline Ventromedial hypothalamic nucleus (VMH) & 17 & $+/++$ & $\mathrm{NR} /++$ \\
\hline Arcuate nucleus (Arc); also known as "Infundibular nucleus" & $17,19-21$ & +++++ & NR \\
\hline Posterior hypothalamus & 19 & + & NR \\
\hline Median eminence, zona externa (MEE) & $17-20$ & NR & $+++/++++$ \\
\hline Median eminence, zona interna (MEI) & 17 & NR & ++ \\
\hline Posterior mammillary nucleus & 17,19 & NR & $+++/++++$ \\
\hline Stria terminalis (st) & $17,19,21$ & NR & $+++/++++$ \\
\hline Premammillary nucleus, ventral part (PMV) & $17,18,21$ & + & + \\
\hline Lateral hypothalamic area (LHA) & $17-21$ & +++ & $++/++++$ \\
\hline Paraventricular hypothalamic nucleus (PVN) & $17-21$ & $+++/++++$ & $+++/++++$ \\
\hline Anterior hypothalamus & 17,19 & + & NR \\
\hline Zona Incerta (ZI) & $17,18,21$ & $+/++$ & ++ \\
\hline Medial forebrain bundle (mfb) & 17,18 & + & ++ \\
\hline Medial preoptic area (MPA) & $16-19,21$ & $+/+++$ & ++++ \\
\hline
\end{tabular}




\begin{tabular}{|c|c|c|c|}
\hline $\begin{array}{l}\text { Structures } \\
\text { Reported to } \\
\text { Contain Nts }\end{array}$ & $\begin{array}{l}\text { Supporting } \\
\text { Literature }\end{array}$ & $\begin{array}{l}\text { Density of } \\
\text { Cell Bodies }\end{array}$ & $\begin{array}{c}\text { Density } \\
\text { of } \\
\text { Fibers }\end{array}$ \\
\hline Ventromedial preoptic nucleus (VMPO) & 18 & ++ & NR \\
\hline Lateral preoptic area (LPO) & $17,18,21$ & ++ & +++ \\
\hline Substantia innominata (SI) & 21 & ++ & NR \\
\hline Anteroventral periventricular nucleus (AVPe) & 18 & ++++ & NR \\
\hline Periventricular hypothalamic nucleus $(\mathbf{P e})$ & $17-21$ & ++ & ++++ \\
\hline Suprachiasmatic nucleus (SCh) & 18,21 & ++ & +++ \\
\hline Posterior pituitary gland & 17,19 & NR & + \\
\hline Pituitary Stalk & 19 & NR & $+++/++++$ \\
\hline Hippocampus & 18 & NR & + \\
\hline \multicolumn{4}{|l|}{ AMYGDALA } \\
\hline Central nucleus of the amygdala (CeA) & $17-19,21$ & +++ & $"+++/++++$ \\
\hline Medial nucleus of the amygdala (Me) & $17,18,21$ & $+/++$ & ++ \\
\hline Basomedial amygdalar nucleus (BMA) & 18,21 & + & +++ \\
\hline Cortical amygdalar nucleus (COA) & 18 & + & +++ \\
\hline \multicolumn{4}{|l|}{ CORTEX } \\
\hline Prepiriform cortex & 18 & NR & $+/+++$ \\
\hline Cerebral cortex $(\mathbf{C x})$ & 18 & NR & +++ \\
\hline \multicolumn{4}{|l|}{ STRIATUM AND FOREBRAIN } \\
\hline Caudate putamen $(\mathrm{CPu})$ & 18 & ++ & ++++ \\
\hline Globus pallidus (GP) & 18 & NR & + \\
\hline Bed nucleus of the stria terminalis (BST) & $17-19,21$ & $+++/++++$ & $++/++++$ \\
\hline Triangular septal nucleus (TS) & 21 & ++ & NR \\
\hline Nucleus of the diagonal band of Broca (DB) & 18,21 & ++ & + \\
\hline Lateral septal nucleus (LS) & 18,21 & ++ & NR \\
\hline Medial septal nucleus (MS) & 21 & ++ & NR \\
\hline Septum pellucidum & 18 & NR & ++ \\
\hline
\end{tabular}

NR not reported;

${ }^{+}$few or sparse;

++ some;

${ }^{+++}$many;

${ }^{++++}$very dense. 
Table 2

Distribution of Nts Cells in the Central Nervous System

Summary of structures reported to contain NtsR1, NtsR2 or NtsR3 cell bodies, using Nts-immunoreactivity or in situ hybridization [30-35] in the rat central nervous system. Results convey the relative density of NtsRlabeled cell bodies.

\begin{tabular}{|c|l|}
\hline \multicolumn{2}{|l|}{ CELL BODIES ONLY } \\
\hline \multicolumn{2}{|l|}{ KEY } \\
\hline NR & Not Reported \\
\hline+ & Few \\
\hline++ & Some \\
\hline+++ & Many \\
\hline++++ & Very Dense \\
\hline
\end{tabular}

\begin{tabular}{|c|c|c|c|c|}
\hline $\begin{array}{l}\text { Structures reported } \\
\text { to contain NtsR }\end{array}$ & $\begin{array}{l}\text { Supporting } \\
\text { Literature }\end{array}$ & NtsR1 & NtsR2 & $\begin{array}{l}\text { NtsR3/ } \\
\text { Sortilin }\end{array}$ \\
\hline \multicolumn{5}{|l|}{ SPINAL CORD } \\
\hline Spinal cord: lamina I and II & 35 & ++ & NR & NR \\
\hline \multicolumn{5}{|l|}{ HINDBRAIN } \\
\hline Oculomotor nucleus (3N) & 33,34 & NR & ++ & ++/ +++ \\
\hline Trochlear nucleus (4N) & 34 & NR & $+/++$ & NR \\
\hline Spinal trigeminal nucleus $(5 \mathrm{~N})$ & 33,34 & NR & + & $+/++$ \\
\hline Abducens nucleus (6N) & 33,34 & NR & + & ++ \\
\hline Facial nucleus (7N) & 33,34 & NR & + & ++ \\
\hline Vestibulocochlear nerve (8N) & 32 & NR & ++ & NR \\
\hline Dorsal motor nucleus of vagus ( $10 \mathrm{~N}$ or DMX) & 33,34 & NR & $-1+$ & $+/++$ \\
\hline Hypoglossal nucleus (12N) & 33,34 & NR & + & $+/++$ \\
\hline Vestibular nuclei (Ve) & $32-35$ & + & + & ++ \\
\hline Cochlear nuclei (CN) & $32-34$ & NR & ++ & $+/++$ \\
\hline Superior colliculus (SC) & $31-34$ & +++ & + & $+/++$ \\
\hline Inferior colliculus (IC) & 33,34 & NR & + & ++/ +++ \\
\hline Trapezoid Nucleus (Tz) & 33,34 & NR & ++ & ++ \\
\hline Mesencephalic reticular nucleus (MRN) & 31,35 & ++ & NR & NR \\
\hline Ventrolateral reticular formation & 30 & +++ & NR & NR \\
\hline
\end{tabular}




\begin{tabular}{|c|c|c|c|c|}
\hline $\begin{array}{l}\text { Structures reported } \\
\text { to contain NtsR }\end{array}$ & $\begin{array}{l}\text { Supporting } \\
\text { Literature }\end{array}$ & NtsR1 & NtsR2 & $\begin{array}{l}\text { NtsR3/ } \\
\text { Sortilin }\end{array}$ \\
\hline Giganotcellular reticular nucleus (Gi) & 34 & NR & + & NR \\
\hline Paragigantocellular reticular nucleus (PGi) & 34 & NR & + & NR \\
\hline Parvocellular reticular nucleus & 34 & NR & $-1+$ & NR \\
\hline Medial reticular formation & 33 & NR & NR & ++ \\
\hline Lateral reticular nucleus & $33-35$ & ++ & + & + \\
\hline Nucleus of the solitary tract (NST) & 33,34 & NR & $-1+$ & $+/++$ \\
\hline Nucleus raphe magnus (RMg) & 34 & NR & $-1+$ & NR \\
\hline Nucleus raphe pallidus (RPA) & 34 & NR & $-1+$ & NR \\
\hline Medial lemniscus (ml) & 33 & NR & NR & $+/++$ \\
\hline Cuneate nucleus $(\mathrm{Cu})$ & 33,34 & NR & + & $+/++$ \\
\hline Gracile nucleus (Gr) & 33 & NR & NR & $+/++$ \\
\hline Inferior olivary complex (IO) & 33,34 & NR & $+/++$ & ++/ +++ \\
\hline Superior olivary complex (SO) & 33,34 & NR & $+/++$ & ++ \\
\hline \multicolumn{5}{|l|}{ MIDBRAIN } \\
\hline Subiculum (S) & $31-34$ & ++ & $++/+++$ & $+/++$ \\
\hline Pontine nuclei & 33,34 & NR & ++ & $+/++$ \\
\hline Periaqueductal gray (PAG) & $31-35$ & $+/++$ & + & $+/++$ \\
\hline Dorsal raphe nucleus (DR) & $31,33,34$ & ++ & + & ++ \\
\hline Median raphe nucleus (MnR) & 33 & NR & NR & $+/++$ \\
\hline Rostral linear nucleus raphe (RLi) & 31,34 & $+/++$ & $-1+$ & NR \\
\hline Tegmental reticular nucleus (TRN) & 31 & +++ & NR & NR \\
\hline Precommissural nucleus (PRC) & 33 & NR & NR & $+/++$ \\
\hline Ventral tegmental area (VTA) & $30-35$ & +++ & + & $+/++$ \\
\hline Interfascicular nucleus (IF) & 34 & NR & $-1+$ & NR \\
\hline Interpeduncular nucleus (IP) & $31,33,34$ & ++ & $-1+$ & $+/+++$ \\
\hline Nucleus of the optic tract & 31 & +++ & NR & NR \\
\hline Nucleus of the posterior commissure (NPC) & 31 & +++ & NR & NR \\
\hline Substantia nigra pars compacta (SNC) & $30-35$ & +++ & ++ & $++/+++$ \\
\hline
\end{tabular}




\begin{tabular}{l|c|c|c|c|c}
\hline $\begin{array}{l}\text { Structures reported } \\
\text { to contain NtsR }\end{array}$ & $\begin{array}{c}\text { Supporting } \\
\text { Literature }\end{array}$ & NtsR1 & NtsR2 & $\begin{array}{c}\text { NtsR3/ } \\
\text { Sortilin }\end{array}$ \\
\hline Red nucleus (R) & & 33,34 & NR & ++ & $++/+++$ \\
\hline Pedunculopontine nucleus (PPTg) & & 31 & $+/++$ & NR & NR \\
\hline Peripeduncular nucleus (PP) & & 31 & + & NR & NR \\
\hline
\end{tabular}

THALAMUS \& NEARBY REGIONS

\begin{tabular}{|c|c|c|c|c|}
\hline Paraventricular thalamic nucleus & $31,33,34$ & + & + & $+/+++$ \\
\hline Rhomboid thalamic nucleus (Rh) & 31 & + & NR & \multirow{2}{*}{$\begin{array}{c}\mathrm{NR} \\
+/++\end{array}$} \\
\hline Reuniens thalamic nucleus (Re) & 31,33 & ++ & NR & \\
\hline Reticular thalamic nucleus (RT) & 33,35 & + & NR & $++/+++$ \\
\hline Mediodorsal thalamic nucleus & 33,34 & NR & $+1++$ & $+/++$ \\
\hline Ventral medial nucleus of the thalamus & 34 & NR & + & NR \\
\hline Posterior nuclear group of thalamus & 33 & NR & NR & ++ \\
\hline $\begin{array}{l}\text { Intermediodorsal nucleus of the thalamus } \\
\text { (IMD) }\end{array}$ & 31 & + & NR & NR \\
\hline Central medial nucleus of the thalamus (CM) & 31 & + & NR & NR \\
\hline Anterodorsal thalamic nucleus (AD) & $31,33,34$ & +++ & $-1+$ & $++/+++$ \\
\hline Anteroventral thalamic nucleus (AV) & 33,34 & NR & + & $+/++$ \\
\hline Suprageniculate nucleus (SGN) & 31 & + & NR & NR \\
\hline Lateral geniculate nucleus (LG) & $31,33,34$ & ++ & + & $+/++$ \\
\hline Medial geniculate nucleus (MG) & $31,33,34$ & ++ & + & ++ \\
\hline Intergeniculate leaflet & 31 & ++ & NR & NR \\
\hline \multicolumn{5}{|l|}{ HYPOTHALAMUS \& NEARBY REGIONS } \\
\hline fimbria of the fornix & 33 & NR & NR & $+/++$ \\
\hline Subparafascicular nucleus (SPF) & 31 & ++ & NR & NR \\
\hline Supramammillary Area Nucleus (SuM) & 30,31 & $+1++$ & NR & NR \\
\hline Mammillary body (MBO) & 33 & NR & NR & ++ \\
\hline Medial mammillary nucleus (MM) & 32 & NR & ++ & NR \\
\hline Lateral mammillary nucleus (LM) & 34 & NR & + & NR \\
\hline Posterior hypothalamus & 31 & +++ & NR & NR \\
\hline Dorsomedial hypothalamic nucleus (DM) & 31 & +++ & NR & NR \\
\hline
\end{tabular}




\begin{tabular}{|c|c|c|c|c|}
\hline $\begin{array}{l}\text { Structures reported } \\
\text { to contain NtsR }\end{array}$ & $\begin{array}{l}\text { Supporting } \\
\text { Literature }\end{array}$ & NtsR1 & NtsR2 & $\begin{array}{l}\text { NtsR3/ } \\
\text { Sortilin }\end{array}$ \\
\hline Ventromedial hypothalamic nucleus (VMH) & 31,33 & ++ & $-1+$ & NR \\
\hline Premammillary nucleus, ventral part (PMV) & 31 & ++ & NR & NR \\
\hline Arcuate nucleus (Arc) & $31-34$ & +++ & $+/++$ & $++/+++$ \\
\hline Lateral Hypothalamic Area (LHA) & $31,33-35$ & $+/+++$ & $-1+$ & $+/++$ \\
\hline Paraventricular hypothalamic nucleus (PVN) & $31,33,34$ & $+/++$ & $-1+$ & ++ \\
\hline Anterior hypothalamus & 31,33 & $++/+++$ & NR & + \\
\hline Zona Incerta (ZI) & $31-35$ & +++ & $-1+$ & ++ \\
\hline Subthalamic nucleus (STN) & 33 & NR & NR & $++/+++$ \\
\hline Nucleus of the lateral olfactory tract (LOT) & 31 & + & NR & NR \\
\hline optic tract (opt) & 33 & NR & NR & $+/++$ \\
\hline Suprachiasmatic preoptic nucleus & 31 & ++ & NR & NR \\
\hline Preoptic periventricular nucleus & 31 & + & NR & NR \\
\hline Supraoptic nucleus (SO) & $31,33-35$ & + & + & $++/+++$ \\
\hline Subparaventricular zone & 31 & $+/++$ & NR & NR \\
\hline Posterior Periventricular nucleus & 31 & + & NR & NR \\
\hline Intermediate Periventricular nucleus & 31 & + & NR & NR \\
\hline Periventricular hypothalamic nucleus (Pe) & $31-33$ & ++ & ++ & $+/++$ \\
\hline Anteroventral Periventricular nucleus & 31 & + & NR & NR \\
\hline Anterior Periventricular nucleus (PVN) & 31 & ++ & NR & NR \\
\hline Nucleus circularis & 31 & ++ & NR & NR \\
\hline Suprachiasmatic nucleus (SCh) & $30-32$ & $++/+++$ & ++ & $+/+++$ \\
\hline Retrochiasmatic area $(\mathbf{R C h})$ & 31,34 & ++ & ++ & NR \\
\hline Hippocampus: Dentate gyrus (DG) & $32-34$ & NR & $-/+$ & $+/++$ \\
\hline Hippocampus: CA1 and CA2 & $32-34$ & NR & $++/+++$ & $++/+++$ \\
\hline Hippocampus: CA3 & 31,33 & ++ & NR & $++/+++$ \\
\hline Lateral Habenula (LHb) & $31-34$ & +++ & $-1+$ & $+/++$ \\
\hline Medial Habenula (MHb) & $31,34,35$ & ++ & $-1+$ & NR \\
\hline \multicolumn{5}{|l|}{ AMYGDALA } \\
\hline Posterior amygdalar nucleus (PA) & 31 & + & NR & NR \\
\hline
\end{tabular}




\begin{tabular}{|c|c|c|c|c|}
\hline $\begin{array}{l}\text { Structures reported } \\
\text { to contain NtsR }\end{array}$ & $\begin{array}{l}\text { Supporting } \\
\text { Literature }\end{array}$ & NtsR1 & NtsR2 & $\begin{array}{l}\text { NtsR3/ } \\
\text { Sortilin }\end{array}$ \\
\hline Central nucleus of the amygdala (CeA) & $31,33-35$ & +++ & ++ & ++ \\
\hline Medial nucleus of the amygdala (Me) & $31,33-35$ & $+/++$ & $-1+$ & $+/++$ \\
\hline Lateral amygdalar nucleus (LA) & 31 & + & NR & NR \\
\hline Basomedial amygdalar nucleus (BM) & 33 & NR & NR & $+/++$ \\
\hline Basolateral amygdalar nucleus (BL) & 31,33 & + & NR & $+/++$ \\
\hline Cortical amygdalar nucleus $(\mathrm{CO})$ & $31,33,34$ & ++ & ++ & ++ \\
\hline Intercalated amygdalar nucleus (IA) & 31 & ++ & NR & NR \\
\hline Anterior amygdalar area $(\mathbf{A A})$ & 31 & + & NR & NR \\
\hline \multicolumn{5}{|l|}{ CORTEX } \\
\hline Retrosplenial area (RS) & $31,33,34$ & + & ++ & $+/+++$ \\
\hline Granular retrosplenial area $(\mathbf{R S P v})$ & 31 & + & NR & NR \\
\hline Occipital cortex / visual cortex & $31,33,34$ & + & $+/++$ & $+/++$ \\
\hline Parietal cortex & 33,34 & NR & ++ & ++ \\
\hline Posterior parietal association areas (PTLp) & 31 & + & NR & NR \\
\hline Somatosensory areas (SS) & 31 & + & NR & NR \\
\hline Visceral area (VISC) & 31 & + & NR & NR \\
\hline Primary motor area (MOp) & 31 & + & NR & NR \\
\hline Secondary motor area (MOs) & 31 & ++ & NR & NR \\
\hline Temporal cortex & 33,34 & NR & $+/++$ & ++ \\
\hline Ventral temporal association area & 31 & + & NR & NR \\
\hline Piriform area (PIR) & $33-35$ & $-1+$ & + & $++/+++$ \\
\hline Entorhinal area (ENT) & $31,33-35$ & +++ & $++/+++$ & $++/+++$ \\
\hline Perirhinal area (PERI) & 31,34 & $+/++$ & + & NR \\
\hline Ectorhinal area $(\mathbf{E C T})$ & 31 & $+/++$ & NR & NR \\
\hline Prelimbic Area (PL) & 31 & ++ & NR & NR \\
\hline Infralimbic Area (ILA) & 31 & ++ & NR & NR \\
\hline Ventral orbital area (ORB) & 31 & ++ & NR & NR \\
\hline Frontal cortex & 33,34 & NR & $+/++$ & $+/++$ \\
\hline
\end{tabular}




\begin{tabular}{|c|c|c|c|c|}
\hline $\begin{array}{l}\text { Structures reported } \\
\text { to contain NtsR }\end{array}$ & $\begin{array}{l}\text { Supporting } \\
\text { Literature }\end{array}$ & NtsR1 & NtsR2 & $\begin{array}{l}\text { NtsR3/ } \\
\text { Sortilin }\end{array}$ \\
\hline Anterior cingulate area (ACA) & $31-34$ & ++ & $+/++$ & $+/+++$ \\
\hline Auditory areas & 31,33 & + & NR & ++ \\
\hline Gustatory areas $(\mathbf{G U})$ & 31 & + & NR & NR \\
\hline Agranular insular area (AI) & 31 & ++ & NR & NR \\
\hline Insular Cortex & 33,34 & NR & $+/++$ & $++/+++$ \\
\hline Endopiriform nucleus (EP) & $31,33,35$ & ++ & NR & ++ \\
\hline \multicolumn{5}{|l|}{ STRIATUM AND FOREBRAIN } \\
\hline Corpus callosum (CC) & 32,33 & NR & ++ & $+/++$ \\
\hline Claustrum & 31,33 & ++ & NR & $+1++$ \\
\hline $\begin{array}{l}\text { Bed nucleus of the accessory olfactory tract } \\
\text { (BA) }\end{array}$ & 31 & + & NR & NR \\
\hline Nucleus accumbens (NA) & $31-34$ & + & $-/++$ & $+/++$ \\
\hline Internal capsule (int) & 31 & + & NR & NR \\
\hline Caudate-putamen & $33-35$ & + & $+/++$ & $+/++$ \\
\hline Globus pallidus & 31 & + & ++ & $+/+++$ \\
\hline Substantia innominata (SI) & $31,32,35$ & $+/++++$ & ++ & NR \\
\hline Parastrial nucleus (PS) & 31 & + & NR & NR \\
\hline Subfornical organ (SFO) & 31,32 & + & ++ & NR \\
\hline Bed nucleus of the stria terminalis (BST) & $31-35$ & $+/++$ & $++/+++$ & $+/++$ \\
\hline Ventral pallidum & 35 & ++ & NR & NR \\
\hline Islands of Cajella (isl) & $31,33-35$ & + & + & ++ \\
\hline Diagonal Band of Broca (DB) & $30,32-35$ & $++1+++$ & $-1+$ & $+/+++$ \\
\hline Taenia tecta (TT) & $31,33,34$ & ++ & + & $++/+++$ \\
\hline Septofimbrial nucleus (SF) & 31 & +++ & NR & NR \\
\hline Triangular nucleus of septum (TRS) & 31 & + & NR & NR \\
\hline Septohippocampal nucleus (SH) & 32,33 & NR & ++ & $+/++$ \\
\hline Lateral Septal nucleus (LS) & $31,33,34$ & $++/+++$ & $+/++$ & $++/++++$ \\
\hline Medial Septal nucleus (MS) & $\begin{array}{l}30,31,33- \\
35\end{array}$ & $++/+++$ & $-1+$ & ++ / +++ \\
\hline Olfactory tubercle (OT) & 34,35 & ++ & ++ & NR \\
\hline
\end{tabular}




\begin{tabular}{|l|c|c|c|c|}
\hline $\begin{array}{l}\text { Structures reported } \\
\text { to contain NtsR }\end{array}$ & $\begin{array}{c}\text { Supporting } \\
\text { Literature }\end{array}$ & NtsR1 & NtsR2 & $\begin{array}{c}\text { NtsR3/ } \\
\text { Sortilin }\end{array}$ \\
\hline Anterior olfactory nucleus (AON) & 33 & NR & NR & $++/+++$ \\
\hline Main olfactory bulb (MOB) & $31,32,34$ & + & $+/++$ & NR \\
\hline
\end{tabular}

NR: not reported.

${ }^{+}$few or sparse;

$+{ }_{\text {some; }}$

++ many;

${ }^{++++}$very dense. 


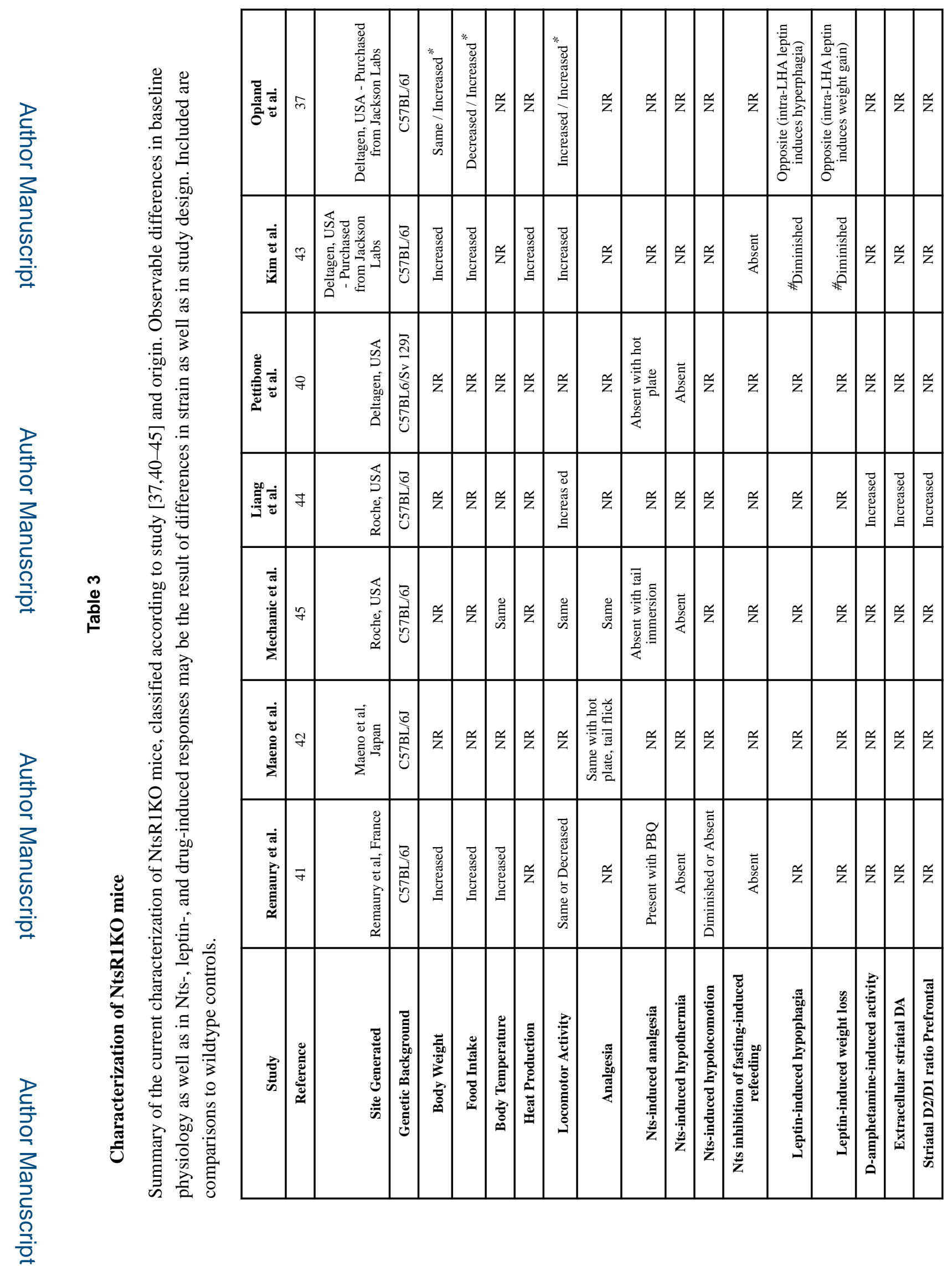

Biochim Biophys Acta. Author manuscript; available in PMC 2019 March 01. 


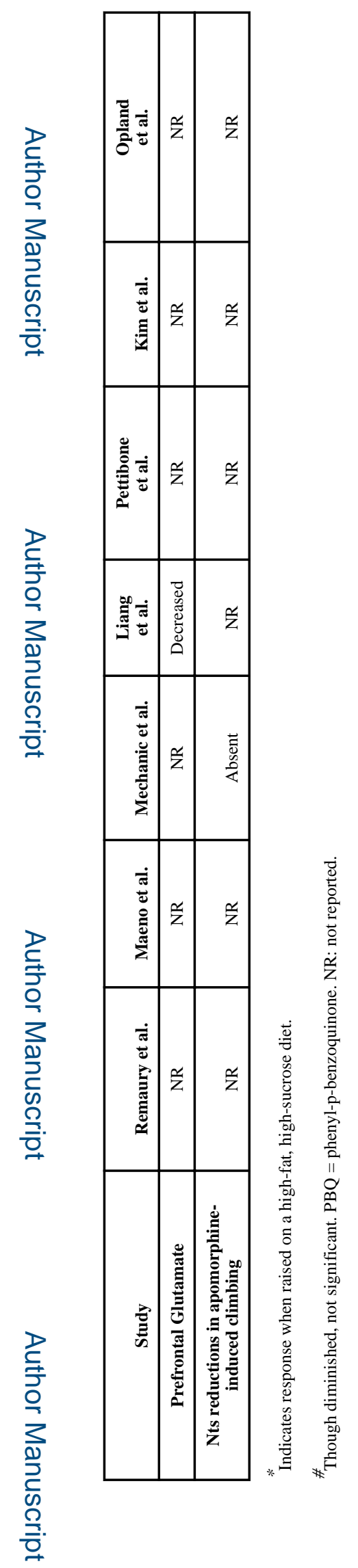

Biochim Biophys Acta. Author manuscript; available in PMC 2019 March 01. 


\section{Table 4}

\section{Brain-wide vs Site-Specific Effects of Nts}

Summary of the literature describing how pharmacologic Nts treatments within the whole brain (via ICV Nts injection) or in specific brain regions modifies physiology.

\begin{tabular}{|c|c|c|c|c|c|c|}
\hline & \multirow{2}{*}{$\begin{array}{c}\begin{array}{c}\text { Non- } \\
\text { specific }\end{array} \\
\text { ICV Nts } \\
\text { injection }\end{array}$} & \multicolumn{5}{|c|}{ Site-specific Nts injection } \\
\hline & & NTS & VTA & VMH & PVN & NAc \\
\hline Analgesia & Increased $^{41}$ & NR & NR & NR & NR & Increased $^{61}$ \\
\hline Blood Pressure & Decreased $^{6,46}$ & Decreased $^{52}$ & NR & NR & NR & NR \\
\hline Hypothermia & Increased $^{41,47}$ & NR & Increased $^{54}$ & NR & NR Slight & -61 \\
\hline Locomotor activity & Decreased $^{47,48}$ & NR & Increased $^{55,56}$ & NR & Slight Decrease ${ }^{60}$ & Decreased $^{62}$ \\
\hline Drinking & Increased $^{49}$ & NR & Decreased $^{57}$ & NR & -60 & NR \\
\hline Feeding & Decreased $^{48,50}$ & Decreased $^{53}$ & Decreased $^{58}$ & Decreased $^{59}$ & Decreased $^{60}$ & .59 \\
\hline Extracellular DA in the NAc & Increased $^{51}$ & NR & Increased ${ }^{56}$ & NR & NR & Decreased $^{63}$ \\
\hline
\end{tabular}

- indicates no change in physiology was observed with Nts injection. NR: not reported. 